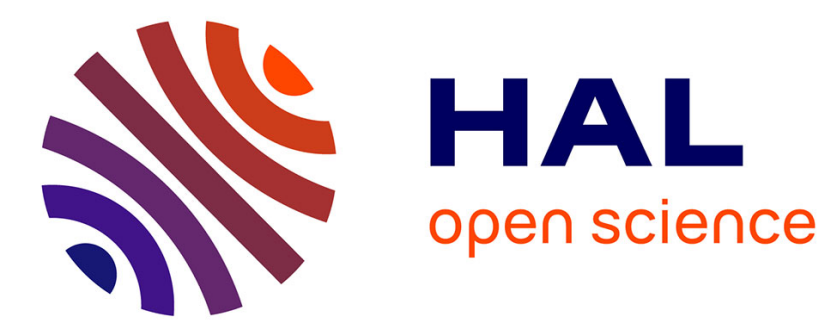

\title{
Cheap talk, monitoring and collusion
}

David Spector

\section{To cite this version:}

David Spector. Cheap talk, monitoring and collusion. 2020. halshs-01983037v4

\section{HAL Id: halshs-01983037 \\ https://shs.hal.science/halshs-01983037v4}

Preprint submitted on 3 Nov 2020

HAL is a multi-disciplinary open access archive for the deposit and dissemination of scientific research documents, whether they are published or not. The documents may come from teaching and research institutions in France or abroad, or from public or private research centers.
L'archive ouverte pluridisciplinaire HAL, est destinée au dépôt et à la diffusion de documents scientifiques de niveau recherche, publiés ou non, émanant des établissements d'enseignement et de recherche français ou étrangers, des laboratoires publics ou privés. 


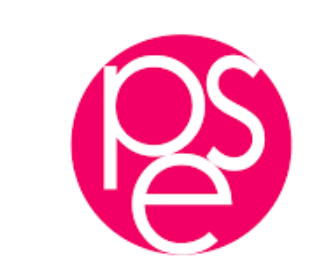

PARISSCHOOL OFECONOMICS
ECOLED'ECONOMIEDE PARIS

WORKING PAPER N 2019 - 03

Cheap talk, monitoring and collusion

David Spector

JEL Codes:

Keywords:

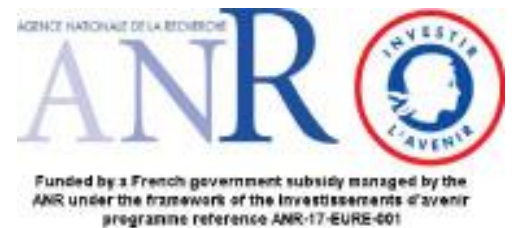




\title{
Cheap talk, monitoring and collusion
}

\author{
David Spector*
}

October 2020

\begin{abstract}
Many collusive agreements involve the exchange of self-reported sales data between competitors, which use them to monitor compliance with a target market share allocation. Such communication may facilitate collusion even if it is unverifiable cheap talk and the underlying information becomes publicly available with a delay. The exchange of sales information may allow firms to implement incentive-compatible market share reallocation mechanisms after unexpected swings, limiting the recourse to price wars. Such communication may allow firms to earn profits that could not be earned in any collusive, symmetric pure-strategy equilibrium without communication.
\end{abstract}

\section{Introduction}

The objective of this paper is to better understand the role of communication in collusive practices.

Collusion, whether tacit of explicit, requires mutual monitoring. ${ }^{1}$ In many recent cartel cases, monitoring took place by having companies compare each other's self-reported sales with some agreed-upon quotas, with a high frequency (often, weekly or monthly). However, these sales reports were for the most part not verifiable, at least in the short run. For instance, in several cases, reliable sales information was available only with a lag of about one year.

Prima facie, this observation is puzzling. If the goal of monitoring is to deter deviations from a collusive agreement, why couldn't a firm wanting to deviate

\footnotetext{
*Paris School of Economics and CNRS. Email: spector@pse.ens.fr

${ }^{1}$ Sugaya and Wolitzky (2018a) show that this general statement is not as universally valid as is often believed, because too precise information on competitors' actions may increase a firm's incentive to deviate from a collusive equilibrium by helping it to identify profitable deviation opportunities.
} 
simply undercut its competitors and misreport its sales at the same time? At first glance, it seems that the only constraint on a firm's incentive to deviate is the amount of time elapsing between the date a deviation occurs and the date it is bound to being revealed to competitors, as reliable sales data become public. How, then, could the exchange of sales reports facilitate mutual monitoring and collusion if it occurs long before sales data can be verified?

Answering this question would contribute to the ongoing debate on the antitrust treatment of information exchanges. In the absence of direct evidence of cartel behavior, competition authorities face a difficult tradeoff. On the one hand, an outright ban on information exchanges would deny companies and consumers the procompetitive benefits that such exchanges may entail. Conversely, a too lenient approach would allow companies to engage in practices that could facilitate collusion and harm consumers. ${ }^{2}$

For instance, in its guidelines on horizontal co-operation between undertakings ${ }^{3}$ the European Commission states that exchanges of information on past sales are not prohibited per se (unlike communication on future behavior) and that they should be assessed under a case-by-case approach. According to K.-U. Kühn, a former Chief Economist of the European Commission, this case-by-case approach should focus on the 'marginal impact' of the information exchanges under scrutiny on the likelihood of collusion. ${ }^{4}$

Accordingly, this paper is an attempt to assess the marginal impact of the early disclosure of sales information long before it becomes public. When 'hard' information is publicly available in any case, should early disclosure be considered harmless cheap talk or a practice facilitating collusion relative to a nocommunication benchmark?

We construct a model showing that, in a market where demand is uncertain and sales data become available with a delay, early communication on sales volumes may make collusion more efficient. Communication may reduce the recourse to price wars as a disciplining device by ensuring that unexpected market share swings are swiftly identified and compensated through short phases of market share reallocation.

Our main finding is that, for some parameter values, collusion with near-

${ }^{3}$ Official Journal of the European Union, C 11/91, 14.1.2011, Communication from the Commission - Guidelines on the applicability of Article 101 of the Treaty on the Functioning of the European Union to horizontal co-operation agreements.

${ }^{4} \mathrm{Kühn}$ (2011) advocates "an analysis of the marginal impact of the information exchange on monitoring or the scope for coordination in the market. If the marginal impact appears small, the case should be closed."
} 
monopoly pricing in all periods along the equilibrium path can occur only if communication is possible, even though such communication does not increase data verifiability.

The collusive equilibrium we derive involves no need for contact between competitors beyond the exchange of sales reports: it is symmetric, which limits the need for pre-play coordination. It involves pure strategies along the equilibrium path, with no need for coordination on a public randomization device. It does not involve interfirm payments.

This suggests that competition authorities should be wary of exchanges of information on past sales, even if they appear to be mere cheap talk and there is no evidence of other interfirm contacts: by itself, such communication can make collusion more efficient and lead to higher prices. Another possible interpretation is that competition authorities should be wary of exchanges of verifiable information on past sales even if such exchanges take place with a long lag, because they can facilitate collusion if they are supplemented with cheap talk taking place with a shorter lag.

The main features of the collusive equilibrium derived in this paper The collusive equilibrium derived in this paper exhibits features similar to those observed in many recent cartels. ${ }^{5}$

- The collusive scheme is based on a target market share allocation. This is indeed the case in many cartels, especially in markets in which prices are not easily observed.

- Colluding firms exchange detailed information on sales volumes at a high frequency. For several cartels, the frequency of such communication was monthly (lysine,${ }^{6}$ zinc phosphate ${ }^{7}$, citric $_{\text {acid }}{ }^{8}$ ), or weekly (vitamins ${ }^{9}$ ).

- When the exchange of self-reported sales data points to a discrepancy between actual and target market shares, companies that sold above their quotas take steps to decrease their sales. According to Harrington (2006),

${ }^{5}$ Harrington (2006), Levenstein and Suslow (2006).

${ }^{6}$ Official Journal of the European Union, L 152/24, 7.6.2001, Case COMP/36.545/F3 Amino Acids, Decision of June 7, 2000, recital 100.

${ }^{7}$ Official Journal of the European Union, L 153/1, 20.6.2003, Case COMP/E- 1/37.027 Zinc phosphate, Decision of December 11, 2001, recital 69.

${ }^{8}$ Official Journal of the European Union, L 239/18, 6.9.2002, Case COMP/E- 1/36.604 Citric acid, Decision of December 5, 2001, recital 100.

${ }^{9}$ Official Journal of the European Union, L 6/1, 10.1.2003, Case COMP/E- 1/37.512 Vitamins, Decision of November 21, 2001, recital 577. 
whereas in some cases cartelists compensated market share swings by making payments to each other (often under the guise of interfirm sales), in other cases the compensation was through market share reallocations of the kind highlighted in this paper, as the continuous monitoring of sales volumes afforded colluding firms "the opportunity to adjust their sales". For instance, "the citric acid and vitamins $A$ and $E$ cartels engaged in 'continuous monitoring' to assess how sales matched up with quotas and, where a firm was at a pace to sell too much by the year's end, the firm was expected to slow down its sales". Likewise, in the zinc phosphate cartel, "customer allocation was used as a form of compensation in the event of a company not having achieved its allocated quota."

- Self-reported sales volumes are not instantaneously verifiable, but they can be compared to reliable data that become public with a lag. This information structure is in line with the facts of several cartels. Reliable information can come from companies' annual reports, verification by independent auditors appointed by the cartelists, import statistics, or the (delayed) publication of tender results. In several recent cases, market share information was found to become available with a delay of about one year. ${ }^{11}$ For instance, in the lysine cartel, "ADM reported its citric acid sales every month to a trade association, and every year, Swiss accountants audited those figures." ${ }^{12}$ In the Copper Plumbing Tubes cartel, ${ }^{13}$ import statistics were a reliable source of information on some producers' sales and helped cartel members to monitor the veracity of

\footnotetext{
${ }^{10}$ One feature of our collusive equilibrium does not coincide with the abovementioned characteristics. The collusive equilibrium we focus on prescribes firms to adjust market shares as soon as sales reports point to a discrepancy relative to target market shares. Whereas such high-frequency adjustments indeed took place in some cases, it appears that they were not prescribed by the collusive agreement, in the sense that a firm's failure to decrease its market share right after communication revealed that it had sold too much was not considered a deviation and did not trigger a punishment phase. This might be explained by the fact that delaying the 'rebalancing' of market shares allows firms to average out random demand shocks and hence reduce the total amount of (often inefficient) market share reallocation.

${ }^{11}$ In our model, we make the strong assumption that the data that become publicly known after a delay are accurate and detailed, whereas in reality they may be noisy and imprecise. Firms may try to conceal some sales from auditors, as noted by Harrington and Skrzypacz (2011); and firms' annual reports, just like cross-country trade data, may not be very disaggregated. However, it must also be noted that the degree of detail that is assumed in our model is not necessary for our results to hold: the assumption that total market sales become public with a lag, without the breakdown by company, would leave our results unchanged.

${ }^{12}$ Lysine decision, recital 100 (underlined by us).

${ }^{13}$ Official Journal of the European Union, L 192/21, 13.7.2006, Case COMP/E-1/38.069 Copper Plumbing Tubes, Decision of 3 September 2004.
} 
the previously exchanged reports, ${ }^{14}$ just like Japanese export statistics allowed companies to check Japanese manufacturers' sales reports in the sorbates cartel. ${ }^{15}$ In the Citric Acid cartel, companies reported information on sales every month ${ }^{16}$ and "the sales figures reported [were] audited by the Schweizerische Treuhandgesellschaft, Coopers 85 Lybrand, which deliver[ed] a regular report on its findings". ${ }^{17}$

Overview of the mechanism at stake The possibility that firms could collude more efficiently by exchanging reports on their own sales may seem surprising because such reports provide no verifiable information in addition to the one that becomes public with a delay in any case. It arises from the following difference between the deterrence of undercutting and the deterrence of misreporting: misreporting can be spotted with certainty once sales information becomes public, whereas, if demand is uncertain enough and only sales information is available, undercutting may not be distinguishable from demand shocks. This implies that misreporting can be deterred at no cost - lies are followed by price wars, but they do not occur in equilibrium - whereas the deterrence of undercutting involves a tradeoff: if sales are an imperfect indicator of behavior, maximal deterrence may require price wars to happen along equilibrium paths. ${ }^{18}$

This contrast underlies our main result. Since misreporting can be detterred at little cost, firms can be induced to truthfully reveal their sales before they become observable to all. This information in turn allows firms to monitor each other more efficiently. ${ }^{19}$

\footnotetext{
14 "First, SANCO manufacturers (...) reported their production and sales volume figures often on a monthly basis to the secretariat. The figures were compiled and circulated among the SANCO club members. Second, until the beginning of the 1990 s, import statistics allowed the control of sales figures, since they were a reliable source for data on production volumes, at least for countries like Belgium, where only one national producer (BCZ) existed." (Copper Plumbing Tubes decision, recital 141).

${ }^{15}$ Harrington (2006), pp. 36-37.

16 "Each of the participants reported the tonnage they had sold in each region (Europe, North America, and the rest of the world) to the secretariat of the ECAMA President by the seventh (day) of each month. In the secretariat these sales figures were assembled and then reported back to the members by telephone, broken down by firm and by region. This made it possible to monitor the relative market shares continuously." (Citric Acid decision, recital 100).

${ }^{17}$ Citric Acid decision, recital 37. This description does not include a mention of the frequency of these regular reports, but it suggests that it was less than every month.

${ }^{18}$ This tension was addressed for the first time in Stigler (1964). See also Green and Porter (1984).

${ }^{19}$ In the Citric Acid decision, it is mentioned that the information exchange allowed colluding firms to 'monitor the correct implementation of [the] quotas and avoid, as far as possible, the need for compensation at the end of each year' (recital 100). In that case, the outcome
} 
Relation to the literature The theoretical literature on the role of communication in collusion comprises two main sets of contributions.

Several papers address pre-play communication in the presence of private information on costs or demand. ${ }^{20}$

Another branch of the literature addresses the role of communication as a private monitoring tool in repeated games. Compte (1998) and Kandori and Matsushima (1998) derive folk theorems, showing that infinitely patient players may achieve maximum profits if they can communicate to facilitate mutual monitoring. ${ }^{21}$

Aoyagi (2002), Harrington and Skrzypacz (2011, 'HS' hereafter) and Chan and Zhang (2015, 'CZ' hereafter) are closely related to this paper since they address the role of non-verifiable sales reports. They show that there may exist collusive equilibria in which companies monitor each other by exchanging sales reports, even though these reports can never be verified. ${ }^{22}$

In contrast to these papers, ours provides a comparative statics result (albeit at the price of highly specific assumptions) about the incremental impact on the feasibility of collusion of communication on past market outcomes. ${ }^{23}$ Our assumptions depart from those in Aoyagi (2002), HS and CZ. They assume that neither price nor sales data ever become public, whereas we assume sales data to become public with a delay. ${ }^{24}$ Also, HS and CZ assume that firms can make direct payments to each other, whereas we rule out such payments. None of these features is inherently more relevant than the others, since both types of information structures and both types of corrective mechanisms are

that colluding firms attempted to avoid thanks to the frequent exchange of sales reports was a need for compensating interfirm payments (which are ruled out by assumption in our model) rather than a price war (as per the theory presented in this paper). Despite this difference, this quote illustrates one of the key ideas of this paper: the role of communication on sales volumes is to allow for frequent market share adjustements so as to avoid less desirable outcomes that might occur, absent communication, if market share swings were detected with a longer delay.

${ }^{20}$ Athey and Bagwell (2001, 2008); see also Aoyagi (2007), Harrington (2017).

${ }^{21}$ See also Obara (2009). A related paper is Rahman (2014), which describes a collusive equilibrium involving mediated or verifiable communication between firms engaged in Cournot competition.

${ }^{22}$ In Aoyagi (2002), sales reports are imprecise, as each firm reports 'low' or 'high' sales depending on whether its sales are below or above a certain threshold.

${ }^{23}$ Athey and Bagwell $(2001,2008)$ also derive comparative statics results on the role of communication. But they relate to a different type of communication in a different setting, namely, pre-play coordination to take into account private information on costs.

${ }^{24} \mathrm{On}$ the general analysis of repeated games in which information on other players' actions is revealed with lags, see Abreu, Milgrom and Pearce (1991). Fudenberg, Ishii and Kominers (2014) study the impact of cheap-talk communication in such games. Igami and Sugaya (2019) provide a quantitative estimate of the impact of the lag on the possibility of collusion on the basis of a stylized model of the vitamins cartel. 
observed. The corrective market share reallocation mechanism highlighted in this paper, however, is probably better suited to the analysis of the cases for which information exchanges are the main legal question, as least from the viewpoint of policy relevance. This is because frequent interfirm payments may provide evidence of unlawful coordination that makes the analysis of information exchanges superfluous for the legal assessment.

To our knowledge, Awaya and Krishna (2016, 'AK' hereafter, which is extended in Awaya and Krishna, 2019a) is the only paper deriving conditions under which communication on past sales increases collusive profits relative to the 'best' equilibrium without communication. However, our model and AK's are relevant to different settings. AK assume that sales data remain private forever. Also, the nature of communication and the way it affects firms' behavior in the collusive equilibrium are very different in their model and in ours. ${ }^{25}$

Organization of the paper We start with an example based on a model characterized by lexicographic preferences in some states of the world (Section 2 ). We derive a necessary condition for a pure-strategy symmetric equilibrium without communication to yield monopoly profits, and a sufficient condition for such profits to be attainable with communication. These results jointly yield a sufficient condition for communication to expand the set of attainable profit levels. We then consider a more general model with a less special demand function (Section 3) a derive a stronger result: for some parameter values, the maximal profits attainable without communication are bounded away from those that can be attained with communication.

\section{An example}

The main result of this paper relies on the following ingredients: (i) sales information (at the firm level, or in aggregate form) becomes public after a lag; (ii) prices are private information; (iii) demand can be zero, which prevents a firm from inferring that a rival undercut the collusive price simply by observing its own zero sales; (iv) asymmetric demand shocks are possible, so that it is not possible to infer from asymmetric market shares that a firm undercut the

\footnotetext{
${ }^{25}$ Another related paper is Mouraviev (2014), which shows that communication can increase collusive profits, albeit in an environment very different from ours since firms can communicate verifiable information and the only limit on communication comes from the risk of being caught colluding and having to pay a fine.
} 
collusive price; (v) aggregate demand is stochastic, so that a firm cannot infer its market share from its own sales.

The model presented hereafter relies on an admittedly special, ad hoc demand function. This is the price to pay in order to obtain a tractable enough model yielding a comparative statics result on the impact of communication rather than merely the characterization of a collusive equilibrium with communication -, with an equilibrium closely resembling what has been observed in several cartels.

\subsection{The model}

\subsubsection{Supply}

There are $n(n \geq 3)$ identical firms producing a heterogeneous good at constant marginal cost $c>0$, and facing the same rate of time preference $\delta$.

\subsubsection{Demand}

There is a continuum of consumers. Its mass is normalized to 1 .

The demand function depends on the state of the world, which is drawn from some (constant) probability distribution. The draws are independent across periods. A state of the world is characterized by two parameters: total demand (which is price-inelastic), and whether demand is 'normal' or 'biased' towards one firm. Total demand can take any value within an interval $S=\left[0, S_{\max }\right)$, with $S_{\max }>0$.

Consumers have unit demand with valuation $V>c$. Demand is either 'normal' or 'biased', as defined hereafter.

Demand in the 'normal' states of the world In a normal state of the world such that total demand is $Q$, consumers consider all $n$ goods as perfect substitutes. Sales are equally split among all the firms setting the lowest price if that price is lower than or equal to $V$.

Demand in the 'biased' states of the world In a biased state of the world, consumers have identical lexicographic preferences that are biased towards Firm $i$ 's product for some $i$. In that case, sales are evenly split among all the firms setting the lowest price (provided this price is lower than $V$ ), unless one of these firms is Firm $i$, in which case all the demand goes to Firm $i$. 
The probability distribution over demand functions The following assumptions about the states of the world and their probability are made throughout the paper.

Irrespective of whether demand is normal or biased, the probability distribution over total demand is absolutely continuous.

The demand function is symmetric across firms in the sense that (i) the distribution of total demand conditional on demand being biased is independent of the identity of the firm in favor of which demand is biased; and (ii) the probability that demand is biased in favor of any particular firm is the same for all firms.

For simplicity, and without any loss of generality, we assume that total expected demand conditional on demand being biased is equal to total expected demand conditional on demand being normal. Let $D$ denote this common expected value.

Demand is biased with some probability $\pi^{B}\left(0<\pi^{B}<1\right)$. Conditional on demand being biased, the distribution of total demand is given by the probability density function $\mu^{B}($.$) over \left(0, S_{\max }\right)$, with $\mu^{B}(Q)>0$ for all $Q \in\left(0, S_{\max }\right)$.

Conditional on demand being normal, the distribution of total demand is characterized by the probability distribution $\mu^{N}$, which has an atom in zero and is characterized by a continuous density function $\mu^{N}(Q)>0$ for $Q \in\left(0, S_{\max }\right)$. The overall probability that demand is zero is denoted $\pi^{L}$ (these notations imply that $\left.\mu^{N}(\{0\})=\frac{\pi^{L}}{1-\pi^{B}}\right) . \operatorname{Max}_{Q} \frac{\mu^{N}(Q)}{\mu^{N}(n Q)}, \operatorname{Max}_{Q} \frac{\mu^{N}(Q)}{\mu^{B}(Q)}$ and $\operatorname{Max}_{Q} \frac{\mu^{B}(Q)}{\mu^{N}(Q)}$ are assumed to be finite.

\subsubsection{The game}

The game is repeated for infinitely many periods, starting in period 1 .

Each period is divided into the following stages.

Stage 1. Firms simultaneously set prices.

Stage 2. The state of the world is determined at random.

Stage 3. Each firm observes the demand addressed to it and serves it.

$\underline{\text { Stage } 4}$ (when communication is possible). Firms simultaneously make a statement on their own sales.

At the end of period $t$, a firm observes only its own sales, the sales made by the other firms in period $t-1$ (if $t \geq 2$ ) and other firms' sales reports (in the variant with communication).

We consider only pure strategies (see the discussion below). In the case 
when communication is not possible, a strategy is an infinite set of functions $\left(s_{1}, s_{2}, \ldots, s_{t}, \ldots\right)$, where $s_{t}$ maps all the information known to a firm at the beginning of period $t$ (i.e. its own past prices and sales and other firms' past observed sales, that is, their sales till period $t-2)$ into the set of possible prices.

When communication is possible, a strategy is an infinite set of functions $\left(s_{1}^{p}, s_{1}^{m}, \ldots, s_{t}^{p}, s_{t}^{m} \ldots\right)$, where $s_{t}^{p}$ maps all the information known to a firm at the beginning of period $t$ (i.e. its own past prices and sales and other firms' past observed sales and reports) into the set of possible prices, and $s_{t}^{m}$ maps all the information known to a firm at the end of period $t$ (i.e. the information known at the beginning of the period plus its own period $t$ price and sales) into the set of possible sales reports.

\subsection{The scope for collusion without communication}

In this section, we address the scope for collusion when communication is impossible. We restrict our attention to pure-strategy equilibria, which is in line with our focus on simple collusive behavior. ${ }^{26}$ Also, we only consider equilibria that are symmetric in the sense that a firm's strategy is invariant to a permutation of other firms' identities, and all firms follow the same strategy. ${ }^{27}$

We derive in this section a sufficient condition for the expected payoffs of pure-strategy, subgame-perfect symmetric equilibria (hereafter, 'PSSE') to be strictly smaller than those corresponding to monopoly profits, that is, $\frac{(V-c) D}{1-\delta}$, when communication is not possible. We start by introducing the following notation:

$$
A=\operatorname{Max}\left(\mu^{N}\left(\left(\frac{S_{\max }}{n}, S_{\max }\right)\right), \mu^{B}\left(\left(\frac{S_{\max }}{n}, S_{\max }\right)\right)\right)
$$

Proposition 1. If the inequality

$$
1+\delta+\delta^{2}+(1-A) \delta^{3}>\frac{1}{n(1-\delta)}
$$

holds, then in any PSSE, the expected sum of total discounted profits is strictly

\footnotetext{
${ }^{26}$ Several recent papers, such as Acemoglu, Bimpikis and Ozdaglar (2009) and Gentzkow and Kamenica (2017) focus on equilibria involving pure strategies along all equilibrium paths, allowing however mixed strategies off equilibrium. It must be acknowledged however that collusive behavior based on mixed strategies along the equilibrium path seems to be observed in some industries (Wang, 2009), in line with theoretical results showing that mixing can improve efficiency (Kandori and Obara, 1998).

${ }^{27}$ Models of collusion often make this assumption (see the discussion in Athey, Bagwell and Sanchirico, 2004).
} 
below $\frac{(V-c) D}{1-\delta}$.

Consider a hypothetical PSSE, denoted $E q^{*}$, that is efficient, in the sense that the expectation of the sum of total discounted profits is $\frac{(V-c) D}{1-\delta}$ in every period. We will prove that (1) cannot hold.

Since total per-period profits cannot exceed $(V-c) D$ and symmetry implies that the expected sum of future discounted profits is identical for all firms, the right-hand side of (1) is equal to each firm's expected sum of future discounted profits, divided by $(V-c) D$. We show now that each of the four terms in the left side of $(1)$ is a lower bound on the profit (divided by $(V-c) D$ ) that a firm could earn in each of the first four periods respectively by slightly undercutting its competitors, assuming these competitors set prices according to $E q^{*}$.

Because of symmetry, $E q^{*}$ prescribes all firms to set the same price in period 1. Efficiency implies that this price is $V$.

Assume that Firm 1 deviates in period 1 and slightly undercuts its competitors. This affords Firm 1 an expected profit arbitrarily close to $(V-c) D$ in period 1. This corresponds to the first term in the left side of (1).

Efficiency requires the minimum price to be $V$ with probability 1 along all possible equilibrium paths of $E q^{*}$ (except possibly for a zero-probability subset of such paths). Since there exists a (nonzero probability) equilibrium path such that all firms sell zero at the end of period 1 (in case demand was zero in period 1), efficiency and symmetry jointly imply that according to $E q^{*}$, a firm that sold zero at the end of period 1 sets price $V$ at the beginning of period 2. Therefore, having slightly undercut its competitors in period 1 , which causes all other firms to sell zero and set again their prices at $V$ at the beginning of period 2, Firm 1 can undercut its competitors again in period 2, which yields an expected period 2 profit arbitrarily close to $(V-c) D$. This corresponds to the second term in the left side of (1).

At the beginning of period 3, after such deviations occured in the first two periods, Firm 1's competitors have two additional pieces of information. Each observes that it sold zero in period 2, and that in period 1 all firms but Firm 1 sold zero and Firm 1 sold some amount $D_{1}$. This information is compatible with some equilibrium path - for instance, zero demand in periods 1 and 2 if $D_{1}=0$, or biased demand in period 1 followed by zero demand in period 2 if $D_{1}>0$. Because of efficiency, $E q^{*}$ thus requires Firms 2 to $n$ to set prices greater than or equal to $V$ in period 3, except possibly for some set $S^{1}$ of values of $D_{1}$ such that $\mu^{B}\left(S^{1}\right)=0$, which implies $\mu^{N}\left(S^{1}\right)=0$ because $\frac{\mu^{N}(Q)}{\mu^{B}(Q)}$ is 
bounded. Therefore, with probability 1, Firm 1 can earn an expected period 3 profit arbitrarily close to $(V-c) D$ in period 3 after undercutting in periods 1 , 2 and 3. This is reflected in the third term in the left side of (1).

At the beginning of period 4, Firm 1's competitors have two new pieces of information: their own zero sales in period 3, and Firm 1's period 2 sales. Their own period 3 zero sales provide no definitive information on Firm 1's period 3 behavior, as zero sales could have been caused by zero demand. Consider now the information conveyed by Firm 1's period 2 sales. For any $Q \in\left[0, \frac{S_{\max }}{n}\right)$, let $p_{2}^{*}(Q)$ denote the price which, according to $E q^{*}$, a firm should set in period 2 after having sold $Q$ in period 1 (symmetry implies that this distribution depends on $Q$ but not on firm identity). If demand is normal in period 1 and total demand is $n Q$, then according to $E q^{*}$ each firm observes that it sold $Q$ and sets price $p_{2}^{*}(Q)=V$ in period 2 (because of efficiency and symmetry) except possibly for a subset $S^{2}$ of values of $Q$ such that $\mu^{N}\left(n S^{2}\right)=0$ (with obvious notations), which implies $\mu^{N}\left(S^{2}\right)=0$ because $\frac{\mu^{N}(Q)}{\mu^{N}(n Q)}$ is bounded. Since a firm cannot observe other firms' sales, a firm that benefitted from biased demand in period 1 and sold $Q \in\left[0, \frac{S_{\max }}{n}\right) \backslash S^{2}$ also sets $p_{2}^{*}(Q)=V$, leaving the possibility that it will have a $100 \%$ market share in period 2 if it benefits from biased demand again. There exists therefore a positive-probability set of equilibrium paths such that Firm 1 has $100 \%$ market share in periods 1 and 2 with period 1 sales smaller than $\frac{S_{\max }}{n}$. Because of efficiency, $E q^{*}$ prescribes Firms 2 to $n$ to set the monopoly price in period 4 after observing such a history (and their own zero sales in period 3). Therefore, if Firm 1 slightly undercuts rivals in periods 1 to 3 and $D_{1} \in\left[0, \frac{S_{\max }}{n}\right) \backslash S^{2}$, which happens with probability at least $1-A$, then Firms 2 to $n$ set prices in period 4 that are greater than or equal to $V$, allowing Firm 1 to undercut them again - hence the fourth term in the left side of (1).

If $E q^{*}$ is an equilibrium, the corresponding sum of discounted expected profits for a firm, equal to the right side of $(1)$ times $(V-c) D$, should be greater than the profits induced by slightly undercutting in the first four periods, which, as is proved above, is greater than the left side of $(1)$ times $(V-c) D .{ }^{28}$ QED

\footnotetext{
${ }^{28}$ Even though the probability that a profitable deviation can occur in period 4 depends on the realization of demand in period 1 , the corresponding expected payoff is still arbitrarily close to $(V-c) D$ because demand realizations are independent across periods.
} 


\subsection{The scope for collusion with communication}

\subsubsection{An informal overview of the role played by communication}

To understand the role of communication, it is helpful to go back to the mechanism underlying Proposition 1. The reason why, absent communication, an efficient PSSE affords a firm the possibility to profitably undercut competitors during the first three periods with probability 1 , and in the fourth period with probability at least $1-A$, is that according to an efficient PSSE, a firm cannot be required to decrease its sales until it knows for sure that demand was biased in its favor. With probability at least $1-A$, a firm observing its sales cannot know whether they represent $100 \%$ of a small demand pool or $1 / n$-th of a large one. A firm that was lucky in period 1 learns it in period 2, is expected to decrease its sales in period 3 , and compliance with this requirement in observed at the end of period 4 .

We consider now the same environment as before, with one addition: at the end of every period, each firm is required to report its sales. The key to the main result is that such communication can expose deviations sooner. To show this, we construct an efficient PSSE with communication, which has the property that a hypothetical deviator would be exposed at the end of period 3 at the latest. Consider a firm undercutting competitors in period 1 and then enjoying a $100 \%$ market share. If this firm lies about its sales, its lie is exposed at the end of period 2. If it does not lie, then, since all firms know their market shares at the end of period 1, a 'lucky' firm can be expected to withdraw from the market in period 2 in order to offset its period 1 luck (assuming demand in period 1 was not zero). Failure to do so would be detected as soon as period 2 sales are observed by all, namely at the end of period 3 (unless period 2 demand is zero). In either case, a deviator cannot conceal its deviation for more than three periods (leaving aside the possibility of zero demand in some periods).

Communication thus allows the existence (for some parameter values) of an efficient PSSE leaving room for profitable undercutting during three periods only, as opposed to four when communication is ruled out. This implies that incentive compatibility is easier to achieve: for some parameter values, collusion at monopoly prices is an equilibrium only if communication is possible. 


\subsubsection{Description of the candidate equilibrium}

We consider the following strategy profiles. There exist integers $k$ and $k^{\prime}$ and a price $p^{w}<c$ such that, at the beginning of a period, the state of the game can be any of the following $\left(n k+k^{\prime}+1\right)$ :

- normal collusion;

- $j$-th period of a price war $\left(1 \leq j \leq k^{\prime}\right)$;

- correction at the expense of some firm $i(1 \leq i \leq n)$ (the 'targeted' firm), with $r$ remaining correction periods $(1 \leq r \leq k)$ ( $n k$ states of the game).

In a nutshell, normal collusion gives way to temporary correction phases whenever sales reports point to asymmetric sales that are compatible with equilibrium behavior (i.e., that can be explained by biased demand). During a correction phase, the firm that sold more than the others in the last normal collusion period sells zero while others set the monopoly price $V$, after which firms return to normal collusion. Any unambiguous evidence of a deviation (like price undercutting or sales misreporting) leads to a price war. ${ }^{29} 30$

The expected duration of a price war and the corresponding below-cost price are such that a firm's expected discounted sum of future profits at the start of a price war is zero. Price wars do not occur in equilibrium.

Prices and messages in the candidate equilibrium Equilibrium actions at the beginning of period $t$ depend only on the state of the game at the beginning of period $t$ :

- If the state of the game at the beginning of period $t$ is 'normal collusion', then all firms set a price equal to $V$;

- If the state of the game at the beginning of period $t$ is 'collusion with a correction at the expense of Firm $i$, then Firm $i$ sets a price equal to $V+1$ whereas all other firms set a price equal to $V$;

\footnotetext{
${ }^{29} \mathrm{As}$ is explained below, transition rules are a bit more complex than this summary description, to account for the possibility that during a correction phase at the expense of some firm, another firm may benefit from biased demand and become the target of a new correction phase.

${ }^{30}$ That price wars cannot occur in equilibrium is in constrast to HS. In HS, the incentive not to misreport sales results from the existence of a function associating to each vector of sales reports the probability of a shift to a noncollusive phase. This function is such that truth-telling is an equilibrium. In our model, the assumption that sales data become public with a lag allows for a simpler mechanism: lies trigger price wars once they are detected.
} 
- If the state of the game at the beginning of period $t$ is 'price war', then all firms set a price equal to $p^{w}$.

Also, in the candidate equilibrium, firms truthfully report their sales.

Transitions between states of the game in the candidate equilibrium The state of the game at the beginning of period 1 is 'normal collusion'. At the beginning of period $t(t \geq 2)$, the state of the game is determined as follows.

- Deviations trigger a price war: if the reported period $(t-1)$ sales are incompatible with the prices prescribed by the candidate equilibrium in period $(t-1)$, or (if $t \geq 3$ ) the reports on period $(t-2)$ sales at the end of period $(t-2)$ do not match the actual period $(t-2)$ sales as observed at the end of period $(t-1)$, then the state of the world in the next period is the first period of a price war.

In all other cases, that is, if the newly available information provides no evidence of a deviation, transition rules are as follows.

- Normal collusion is followed by normal collusion if period $(t-1)$ reported sales are equal; and otherwise a correction phase with $k$ remaining periods at the expense of the only firm that reported nonzero sales.

- Price wars start over unless reported sales are equal and strictly positive. If the state of the game at the beginning of period $(t-1)$ is ' $r$-th period of a price war' with $r \leq k^{\prime}$, then (i) if reported period $(t-1)$ sales are equal and strictly positive, then the state of the game at the beginning of period $t$ is ' $(r+1)$-th period of a price war' if $r<k^{\prime}$ and 'normal collusion' if $r=k^{\prime}$; (ii) otherwise, it is 'first period of a price war'.

- At the end of a correction period at the expense of Firm $i$ with $r$ remaining periods, if the reported period $(t-1)$ sales of all firms other than Firm $i$ are equal, then at the beginning of period $t$ the state of the game is 'normal collusion' if $r=1$ and 'correction at the expense of Firm $i$ with $(r-1)$ remaining periods' if $r>1$. If only one firm (say Firm $j, j \neq i$ ) reported nonzero sales, then at the beginning of period $t$ the state of the world is 'correction at the expense of Firm $j$, with $k$ correction periods remaining'.

This candidate equilibrium is symmetric, involves only pure strategies and yields expected total profits $(V-c) D$ in every period. 
2.3.3 A sufficient condition for the candidate equilibrium to be an actual equilibrium

Proposition 2. If $\pi^{B}$ and $\pi^{L}$ are close enough to zero and there exists an integer $\mathrm{k}$ such that Conditions (2) and (3)

$$
\begin{aligned}
& n(1-\delta)(1+\delta)<\delta^{k} \\
& n(1-\delta)+\delta^{k+1}<1
\end{aligned}
$$

hold, then there exist a positive integer $k^{\prime}$ and a price $p^{w}$ such that the above strategy profiles correspond to a PSSE (with correction phases lasting $\mathrm{k}$ periods and price wars lasting $\mathrm{k}^{\prime}$ periods with price $\left.p^{w}\right)$. In this equilibrium, expected total profits are $(V-c) D$ in all periods.

Proposition 2 is a limit case of a stronger result holding under more general assumptions (Proposition 5, in the next section, the detailed proof of which is in the appendix). We provide here a sketch of the proof.

First, given the transition rules stated above and the fact that expected profits are strictly positive at the end of a price war, one can find (by continuity) a pair $\left(p^{w}, k^{\prime}\right)$ such that, in expectation, the losses incurred during a price war exactly offset these future profits so that a firm's expected sum of future discounted profits at the start of a price war is zero. We consider such a pair.

Second, if $\pi^{B}$ and $\pi^{L}$ are close enough to zero, then undercutting leads a deviator to have a $100 \%$ market share with a probability close to 1 .

(2) can be written $(1+\delta)(V-c) D<\frac{\delta^{k}}{1-\delta} \frac{(V-c) D}{n}$. (2) implies that it is optimal for a firm targeted by a correction period to follow the prescriptions of the candidate equilibrium. If it undercuts the other firms, it earns $(V-c) D$ in expectation but its (almost certain) 100\% market share willl be detected at the end of the next period, triggering a price war, so that the best it can do is report zero sales and undercut again, after which a price war starts. The deviator's profits would thus be monopoly profits during two periods, and in expectation zero thereafter. This is captured by the left side of (2).

The right side corresponds to the expected profit of a firm complying with the prescriptions of the candidate equilibrium at the start of a correction period targeting it (namely, zero for $k$ periods and $1 / n$-th of total profits thereafter): if $\pi^{B}$ is small, the correction phase will not be interrupted by the start of a new one targeting another 'lucky' firm. (2) implies that complying by the prescriptions of a correction period is optimal. If $\pi^{B}$ and $\pi^{L}$ are close to zero, (2) also implies 
that a firm that benefitted from biased demand during a 'normal collusion' phase is better off by not lying: misreporting and undercutting would lead to monopoly profits during one additional period, which is less than the left side of (2), whereas exposing itself to a correction phase as prescribed would yield in expectation the right side.

(3) is equivalent to $(V-c) D+\frac{\delta^{k+1}}{1-\delta} \frac{(V-c) D}{n}<\frac{1}{1-\delta} \frac{(V-c) D}{n}$. This inequality implies that it is optimal not to undercut in a 'normal collusion' period: the right side is equal to the expected sum of future discounted profits of a firm complying with the prescriptions of the candidate equilibrium, whereas the left side corresponds to a specific deviation, namely undercutting and then truthfully reporting sales (which is more profitable than lying) and complying with the prescriptions of the candidate equilibrium forever after. (2) and (3) together imply that there is no profitable deviation (for a systematic analysis, see the proof of Proposition 5 in the appendix).

\subsection{Comparative statics: the marginal impact of communication}

Combining Propositions 1 and 2 provides a sufficient condition for communication to expand the set of the profits attainable in a PSSE: this is the case if conditions (1), (2) and (3) are simultaneously satisfied.

Proposition 3. For each $\mathrm{n}$ between 3 and 10, there exist parameter values such that, if communication is possible, there exists a PSSE leading to a discounted sum of total expected profits equal to $\frac{(V-c) D}{1-\delta}$, whereas if communication is not possible, there exists no such PSSE.

The proof of this result (a consequence of Proposition 6, the proof of which is in the appendix) has two main parts. First, we prove that there exist triplets $(n, \delta, k)$ such that conditions (1)-(3) jointly hold when $A=0$ (Figure 1) and, by continuity, for some strictly positive $A>0$. Figure 1 displays intervals of values of $\delta$ satisfying (1)-(3) for selected values of $n$ and $k$ and $A=0$ (and therefore for some $A>0$ by continuity). ${ }^{31}$ Second, considering a set of triplets $(n, \delta, k)$ such that (1)-(3) hold for some $A>0$, we show that one can construct a family of demand functions such that $\pi^{B}$ and $\pi^{L}$ are arbitrarily close enough to zero and $\operatorname{Max} Q \frac{\mu^{N}(Q)}{\mu^{N}(n Q)}, \operatorname{Max}_{Q} \frac{\mu^{N}(Q)}{\mu^{B}(Q)}$ and $\operatorname{Max}_{Q} \frac{\mu^{B}(Q)}{\mu^{N}(Q)}$ are bounded.

INSERT FIGURE 1.

\footnotetext{
${ }^{31}$ For the sake of readability, we present these results in terms of the discount rate applied over a period, that is, the rate $\rho$ such that $\delta=\frac{1}{1+\rho}$.
} 


\subsection{The limits of the above results}

The granularity of sales data. The above results do not require an informational assumption as strong as ours. The strategies in the equilibrium with communication could be implemented under the weaker assumption that reliable data on total rather than individual market sales become available after a one-period lag. Such information would allow firms to detect that some firm lied, by comparing actual and reported total sales, and comparing total reported sales with its own individual sales would allow each firm to calculate its market share. Since, in the equilibrium with communication displayed above, the price war following a lie treats all firms symmetrically, the lack of information on a liar's identity would make no difference. Therefore, communication through a third party that collects firms' own-sales reports and communicates to all firms total sales data based on these reports would be sufficient for Proposition 2 to hold. ${ }^{32}$

At least three firms. With more than three firms, if a firm sets a price above consumers' valuation $V$ in a 'normal collusion' period, the ensuing sales distribution is incompatible with any equilibrium path if demand is neither zero nor biased since all firms but one sell nonzero amounts, and there is no way for a firm to conceal such a deviation (it could not report the same sales as other firms because it would not know them), so that a price war would ensue. With only two firms, such a deviation cannot be ruled out as simply: if a firm sets a price above the monopoly level, this would lead to sales looking like the result of biased demand in favor of its competitor, which could trigger a correction phase at the expense of this competitor. Having more than three firms dispenses us from considering such deviations.

No interfirm payments. Our results would not hold if interfirm payments were possible. In that case, a sales imbalance in period 1 could trigger compen-

\footnotetext{
${ }^{32}$ This remark is at odds with the oft-made claim that "aggregating the data /on firms" historical and current prices, costs, and output] largely removes the value of information in facilitating collusion" (Carlton, Gertner and Rosenfield, 1997). Awaya and Krishna (2020) present another mechanism through which the communication of credible aggregate sales data to individual firms can facilitate collusion. In their model (unlike those in their 2016 and 2019a papers) firms have an incentive to misreport sales, hence the need for "Swiss accountants". It must be noted that in some models, more accurate information may decrease the set of attainable profits because it may help firms to identify more profitable deviations (Sugaya and Wolitzky, 2018a). However, such a mechanism cannot be present in our model, since the deviations considered here do not rely on the deviating firm's information on other firms' sales.
} 
sating payments at the end of period 2 , just after it is publicly observed, even without communication.

Symmetric strategies. The restriction to symmetric strategies is crucial to our results. Absent this restriction, one could envision collusive equilibria without communication such that companies take turns and in each period, one serves the entire demand while the others set prohibitively high prices. The informational problem that communication is meant to solve would not exist because deviations would be spotted as soon as sales data become observable.

Pure strategies. If mixed strategies were considered, one could envision candidate equilibria such that prices are drawn from an atomless distribution. A firm making nonzero sales would know that its market share is $100 \%$ right after observing its own sales. This would remove the informational problem that communication is meant to solve even without communication.

Lexicographic demand. This restriction, made for expositional simplicity, makes the results weaker than they would be under a less extreme modeling of demand (see below). This assumption is relaxed in the next section.

Which bound on collusive profits without communication? Proposition 3 provides no lower bound on the incremental impact of communication on collusive profits. In fact, under lexicographic preferences, the reasoning behind Proposition 1 cannot be extended to provide a strictly positive lower bound. A crucial step in the proof of Proposition 1 is that in an efficient PSSE without communication, a reallocation of markets shares (by having a lucky firm withdraw from the market) cannot immediately follow a market share imbalance. Reallocation can take place only after firms learn their market shares and the lucky firm realizes it was lucky. But the reason for this is the efficiency requirement: if the minimum price must be the monopoly price $V$, then a firm can withdraw only by setting a price above consumers' willingness to pay, and it would be inefficient for all firms to do so, each wrongly believing it is the only 'lucky' firm. However, giving up an arbitrarily small fraction of expected equilibrium profits would allow a market share reallocation phase to take place immediately after a biased demand period, without waiting for firms to learn that there was an imbalance. Consider any arbitrarily small $\varepsilon>0$. A strategy prescribing that a firm sets price $V-\varepsilon$ after it sold zero and $V$ otherwise would 
cause a market share reallocation following biased demand, at a cost to total profits of only $\varepsilon$. This is because under lexicographic preferences, a firm setting a price slightly above its competitors', however small the difference, sells zero even if demand is biased in its favor. Therefore, the above results prove that communication may be required to achieve monopoly profits, but they do not prove that communication can increase the maximum attainable profits.

In the next section, we prove that the above results can be strengthened under a less extreme modeling of demand: communication may increase the maximum attainable profits.

\section{A more general model: communication may in- crease the maximum attainable profits}

In this section, we relax the assumption of lexicographic preferences in the case of biased demand. This allows us to state a stronger result.

\subsection{Assumptions: a less special demand function}

The only change in assumptions is that when demand is biased in favor of some firm, say Firm $i$, the relative preference for that firm's product is stronger than implied by lexicographic demand: in that case, consumers' valuation for product $i$ is some $v>V$. It is assumed, like in the previous section, that if consumers are indifferent between the several firms' offers, demand is split equally between them.

Consumers' willingness to pay for product $i$ when demand is biased in favor of Firm $i$ is drawn from some probability distribution $\nu$ over some interval $\left(V, V^{\prime}\right)$ with $V^{\prime}>V$. For the sake of tractability, $\nu$ is assumed to be the uniform distribution. The ratio $\left(V^{\prime}-V\right) /(V-c)$ is denoted $u$.

\subsection{Collusion without communication}

With this modified demand, Proposition 1 can be strengthened: Proposition 4 states a condition for the non-existence of equilibria approaching total expected profits of $(V-c) D$ per period, when firms cannot communicate. Its proof (appendix) is more complex than that of Proposition 1 but it follows the same logic. 
Proposition 4. If inequality (1) stated in Proposition 1 holds and $\pi^{L}, \pi^{B}$, $\frac{\pi^{B} u}{\pi^{L}}$ and $\frac{n u}{(1-\delta) \delta^{3} \pi^{B} \pi^{L}(1-A)}$ are close enough to zero, then total expected perperiod profits in all PSSE are bounded away from $(V-c) D$ : there exists $\sigma>0$ such that in any PSSE, the expected sum of all firms' future discounted profits is smaller than or equal to $\frac{(V-c) D}{1-\delta}(1-\sigma)$.

We explain hereafter why the various expressions mentioned in the statement of Proposition 4 must be close to zero. Just like for Proposition 1, the proof is based on showing that, if a hypothetical equilibrium exists that yields total profits close enough to $\frac{(V-c) D}{1-\delta}$, then it prescribes strategies that would allow a firm (say, Firm 1) to profitably undercut and earn in expectation almost $(V-c) D$ in each of the first four periods. Since in periods of biased demand, consumers' willingness to pay for their favorite good is $V^{\prime}>V$, the greatest possible expected total per-period profit is not $(V-c) D$ anymore but rather $(V-c) D\left(1+\pi^{B} u\right) \cdot \pi^{B} u$ should be small enough so that for the sum of total expected profits to be close to $\frac{(V-c) D}{1-\delta}$, profits must be close enough to $(V-c) D$ in each of the first four periods (those considered in the proof). Also, a key element of the proof of Proposition 1 is that the 'suspicious' observation that Firm 1 was the only firm with nonzero sales in periods 1 and 2 , and other firms again had zero sales in period 3 is still compatible with some equilibrium path (if Firm 1's period 1 sales were below $\frac{S_{\max }}{n}$, so that it could not infer it had a $100 \%$ market share) - and thus does not trigger a price war. If the question is now about approaching per period profits of $(V-c) D$, it must be the case that the probability for this observation to occur in equilibrium (i.e., the probability of an 'innocent' explanation for this suspicious observation) is large enough: otherwise, it could trigger a price war without much impact on total expected profits. The probability that demand is biased in the first two periods, towards the same firm, that it is zero in period 3, and that the 'lucky' firm's period 1 sales are below $\frac{S_{\max }}{n}$, is greater than $\frac{\left(\pi^{B}\right)^{2} \pi^{L}(1-A)}{n}$. This probability should be high relative to the maximum possible 'upward' deviation of profits in excess of $(V-c) D$, namely $\pi^{B} u$, which could occur in the first period and be 'compensated' downwards during the fouth (and last) deviation period, hence the division by $\delta^{3}$, leading to the condition that $\frac{n u}{(1-\delta) \delta^{3} \pi^{B} \pi^{L}(1-A)}$ should be close to zero. By the same reasoning, the probability that all firms observe zero sales at the end of Period 1 is $\pi^{L}$, implying that $\frac{\pi^{B} u}{\pi^{L}}$ should be close to zero. Also, since the proof is based on showing that repeated undercutting is profitable, it is facilitated by having $\pi^{B}$ close to zero, since a very small price 
undercutting is profitable only if demand is not biased, i.e., with probability $1-\pi^{B} \cdot 33$

\subsection{Collusion with communication}

The equilibrium with communication described in Section 2 is also an equilibrium in the modified model considered in this section, with a more general, non-lexicographic demand structure, under the same conditions on parameters, provided preferences when demand is 'biased' are close to lexicographic. The only difference with the equilibrium strategies described in Section 2.3 is that in a correction period at the expense of a firm, that firm sets a price equal to $V^{\prime}+1$, rather than $V+1$ (in order to ensure zero sales).

Proposition 5. If $\pi^{B}, \pi^{L}$ and $u$ are close enough to zero and there exists an integer $\mathrm{k}$ such that inequalities (2) and (3) stated in Proposition 2 hold, then there exist a positive integer $k^{\prime}$ and a price $p^{w}$ such that the strategy profiles described in Section 2.3 correspond to a PSSE (with correction phases lasting $\mathrm{k}$ periods and price wars lasting $\mathrm{k}$ 'periods with price $\left.p^{w}\right)$. In this equilibrium, expected total profits are $(V-c) D$ in all periods.

\subsection{Comparative statics: the marginal impact of commu- nication}

The same comparative statics result holds as in Section 2: for some parameter values, communication allows firms to attain collusive profits that are not attainable without communication.

Proposition 6. For each $\mathrm{n}$ between 3 and 10, there exist parameter values such that, if communication is possible, there exists a PSSE leading to a discounted sum of total expected profits $\frac{(V-c) D}{1-\delta}$, whereas if communication is not possible, this sum, considered over all PSSE, is bounded away from $\frac{(V-c) D}{1-\delta}$.

The proof of this result is in the appendix. It has two main parts. First, we prove that there exist triplets $(n, \delta, k)$ such that conditions (1)-(3) jointly hold when $A=0$ (Figure 1) and, by continuity, for some strictly positive $A>0$.

\footnotetext{
${ }^{33}$ The condition that $\pi^{L}$ should be close to zero is not strictly necessary for Proposition 4 to hold, but it simplifies the proof. Since the main result of the paper is Proposition 6, namely, the existence of parameters such that communication increases maximal attainable collusive profits, and the existence of a high-profit equilibrium with communication requires $\pi^{L}$ to be small (Proposition 5, see also the informal discussion of Proposition 2), this condition does not restrict the main contribution of this paper.
} 
Second, considering a set of triplets $(n, \delta, k)$ such that (1)-(3) hold for some $A>$ 0 , we show that one can construct a family of demand functions such that $\pi^{L}$, $\pi^{B}, \frac{\pi^{B} u}{\pi^{L}}$ and $\frac{n u}{(1-\delta) \delta^{3} \pi^{B} \pi^{L}(1-A)}$ and $\frac{n u}{\left(1-\delta_{\max }\right) \delta_{\min }^{3} \pi^{B} \pi^{L}(1-A)}$ are arbitrarily close enough to zero and $\operatorname{Max}_{Q} \frac{\mu^{N}(Q)}{\mu^{N}(n Q)}, \operatorname{Max}_{Q \frac{\mu^{N}(Q)}{\mu^{B}(Q)}}$ and $\operatorname{Max} x_{Q} \frac{\mu^{B}(Q)}{\mu^{N}(Q)}$ are bounded.

\section{Conclusion}

The model presented in this paper casts light on the marginal impact of communication on the feasibility of collusion: the exchange of sales reports may lead to higher prices because it facilitates the recourse of colluding firms to incentivecompatible market share reallocation mechanisms, limiting the need for price wars. This result, which is similar to Awaya and Krishna's $(2016,2019)$ but applies to a different information structure and involves a different relationship between the information that is exchanged and firms' subsequent actions, may be present even though the information exchange is mere cheap talk, in the sense that it does not make sales data verifiable sooner.

While the assumption that sales data become public after a delay is strong, it nevertheless is relevant to many markets. Also, our results are robust to weakening this assumption. Assume for instance that sales data become public after being audited by third parties (as was the case in several cartels mentioned in the introduction as a motivation for this paper). If a firm that undercuts its competitors and increases its sales as a result can, with a small probability, succeed in concealing some sales from its auditor, then our results should carry over, since the profitability of undercutting is a continuous function of the probabilities of the various states of the world in the subsequent periods.

Turning to the implications for antitrust enforcement, our results suggest that the exchange of sales reports should be considered suspicious if reports revealing market share swings lead to prompt compensating movements, to an extent that cannot be explained by individual firms' unilateral profit maximization behavior, given the intertemporal pattern of demand shocks. Competition authorities should not rule out the possibility that communication is meant to facilitate such compensation mechanisms, even if the data that are exchanged between firms are not verifiable when communication takes place, and communication does not affect the date at which they will become verifiable. Conversely, the public dissemination of verifiable sales data may conducive to collusion even if it takes place with a long lag, because it can be supplemented with private 
communication on non-verifiable sales data that takes place with a shorter lag. It may therefore warrant more public scrutiny.

Also, since our results continue to hold under the assumption that the data becoming public after a lag are about total sales only, they imply that the dissemination of aggregated sales data by trade associations, based on firms' self-reported sales, may facilitate collusion.

Admittedly, our model relies on special and restrictive assumptions about demand. This is in our view the price to pay in order to estimate an upper bound on firms' profits in all (pure strategy, symmetric) equilibria without communication, which then allows us to state results on the marginal effect of communication. This is because little is known yet on bounds on equilibrium payoffs in infinitely repeated games under general assumptions (except at the limit when players are almost infinitely patient). However, recent advances on this topic may pave the way for additional results on the marginal impact of communication under less special assumptions. ${ }^{34}$ This should be the focus of future research.

\section{Appendix}

Proof of Proposition 4. We introduce the following notations: $\lambda_{1}$ denotes $\operatorname{Max}\left(\underset{Q \in\left(0, S_{\max }\right)}{\operatorname{Max}} \frac{\mu^{N}(Q)}{\mu^{B}(Q)}, \underset{Q \in\left(0, S_{\max }\right)}{\operatorname{Max}} \frac{\mu^{B}(Q)}{\mu^{N}(Q)}\right)$ and $\lambda_{2}$ denotes $\underset{Q \in\left(0, \frac{S_{\max }}{n}\right)}{\operatorname{Max}} \frac{\mu^{N}(Q)}{\mu^{N}(n Q)}$.

We consider a hypothetical PSSE $E q *$ such that the the expected sum of all firms' future discounted profits is greater than $\frac{(V-c) D}{1-\delta}(1-\sigma)$ for some small $\sigma$. The core of this proof is the calculation of a lower bound on the profits that some firms, say Firm 1, could earn by following a certain strategy, which can be interpreted as undercutting in each of the first four periods. This requires intermediate results about the strategies followed by Firms 2 to $n$ conditional on the information available to them.

Step 1. Minimum combined profits after certain histories. We define the history of the game till period $t$ as the sequence of prices and sales till period $t$ included. We provide hereafter a lower bound on the expectation of total period $t$ profits conditional on past history belonging to some set $H$. Let $\operatorname{Prob}(H)$ denote the probability, according to $E q *$, that the history of the game till period $(t-1)$

\footnotetext{
${ }^{34}$ See in particular Pai, Roth and Ullman (2016) and Sugaya and Wolitzky (2017, 2018b). Awaya and Krishna $(2016,2019 a)$ also overcome this difficulty by characterizing an upper bound on collusive profits in the no-communication case under quite general assumptions.
} 
belongs to $H$ (and let it be equal to 1 if $t=1$ ). Since total expected profits in any period cannot exceed $(V-c) D\left(1+\pi^{B} u\right)$, the expected discounted sum of total profits in all periods cannot exceed $(V-c) D\left(1+\pi^{B} u\right)\left(\frac{1}{1-\delta}-\delta^{t-1} \operatorname{Prob}(H)\right)+$ $\delta^{t-1} \operatorname{Prob}(H) \prod(H)$, where $\prod(H)$ denotes expected total period $t$ profits conditional on past history belonging to $H$. This expected discounted sum is greater than $\frac{(V-c) D(1-\sigma)}{1-\delta}$, implying that $\Pi(H)>(V-c) D\left(1-\alpha_{t}(\operatorname{Prob}(H), \sigma)\right)$ with $\alpha_{t}(x, \sigma)=\frac{\sigma+\pi^{B} u}{x(1-\delta) \delta^{t-1}}$.

Step 2. A quasi-lower bound on equilibrium prices. Assume that in period $i$, conditional on a certain event (a set of past histories), the expectation (according to $E q *)$ of total profits $\prod$ is greater than $(V-c) D(1-\alpha)$ for some $\alpha$. Defining $g(\alpha)=\sqrt{\frac{\alpha+\pi^{B} u}{1-\pi^{B}}}$, the probability (conditional on that same event) that the lowest of all $n$ prices in period $i$ is greater than $c+(V-c)(1-g(\alpha))$ is greater than $1-g(\alpha)$. Proof: total expected profits cannot exceed $D\left(\operatorname{Min}\left(p_{t}^{1}, \ldots, p_{t}^{n}, V\right)-c\right)$ if demand is normal and $(V-c) D(1+u)$ otherwise. If the probability that $\operatorname{Min}\left(p_{t}^{1}, \ldots, p_{t}^{n}\right)-c<(V-c)(1-g(\alpha))$ is greater than $g(\alpha)$, then $\frac{\prod}{(V-c) D}<$ $\pi^{B}(1+u)+\left(1-\pi^{B}\right)(1-g(\alpha)+g(\alpha)(1-g(\alpha)))=1-\alpha$.

Step 3. The profit from deviating in period 1. Since $E q *$ is symmetric, it prescribes all firms to set the same price $p_{1}^{*}$ in period 1 . The total expected profit induced by $E q *$ in period 1 is thus less than or equal to $D\left(p_{1}^{*}-c\right)$, implying that $p_{1}^{*}-c>(V-c)\left(1-g_{1}\right)$, with $g_{1}=\alpha_{1}(1, \sigma)$. If Firm 1 deviates and sets a price equal to $p_{1}^{\text {dev }}=c+(V-c)\left(1-g_{1}\right)$ in period 1 , it serves the entire demand if demand is normal or biased in its favor, i.e., with a probability exceeding $1-\pi^{B}$

Step 4. Firm 1's possible deviation in period 2. Since $E q *$ is symmetric, there exists $p_{2}^{*}(0)$ such that $E q *$ prescribes a firm that sold zero in period 1 to set price $p_{2}^{*}(0)$ in period 2 . The equilibrium probability that all firms sell zero in period 1 is $\pi^{L}$. Step 1 implies that $p_{2}^{*}(0)>c+(V-c)\left(1-\alpha_{2}\left(\pi^{L}, \sigma\right)\right)$. Let $g_{2}$ denote $\alpha_{2}\left(\pi^{L}, \sigma\right)$. If Firm 1 deviates in period 2 by setting a price $p_{2}^{d e v}=c+(V-c)\left(1-g_{2}\right)$ and all other firms made zero profits in period 1 , its expected period 2 profit is greater than $(V-c) D\left(1-g_{2}\right)\left(1-\pi^{B}\right)$.

Step 5. Firm 1's possible deviation in period 3. For each $Q$ in $\left(0, S_{\max }\right]$, let $p_{3}^{*}(Q)$ denote the price prescribed by $E q *$ in period 3 for a firm having observed that (i) it sold zero in period 2; and (ii) in period 1, one of the firms (not itself) sold $Q$ while all others sold 0 . We also define $g_{3}^{*}(Q)$ by the identity $p_{3}^{*}(Q)-c=(V-c)\left(1-g_{3}^{*}(Q)\right)$. The equilibrium probability that (i) Firms 2 to $n$ had zero sales in periods 1 and 2 and (ii) Firm 1 had nonzero sales in period 1 is greater than $\frac{\pi^{B}}{n} \pi^{L}$. Steps 1 and 2 imply that conditional on (i) 
and (ii), with probability greater than $1-g\left(\alpha_{3}\left(\frac{\pi^{B}}{n} \pi^{L}, \sigma\right)\right)$, the minimum of all prices in period 3 is above $c+(V-c)\left(1-g\left(\alpha_{3}\left(\frac{\pi^{B}}{n} \pi^{L}, \sigma\right)\right)\right)$ : there exists $S_{3} \subset\left(0, S_{\max }\right)$ such that (i) $\mu^{B}\left(S_{3}\right)>1-g\left(\alpha_{3}\left(\frac{\pi^{B}}{n} \pi^{L}, \sigma\right)\right)$ and (ii) $\forall Q \in$ $S_{3}, g_{3}^{*}(Q)<g_{3}$. Also, by the definition of $\lambda_{1}, \mu^{N}\left(S_{3}\right)>1-\lambda_{1} g\left(\alpha_{3}\left(\frac{\pi^{B}}{n} \pi^{L}, \sigma\right)\right)$. Define $p_{3}^{d e v}=c+(V-c)\left(1-g_{3}\right)$ with $g_{3}=g\left(\alpha_{3}\left(\frac{\pi^{B}}{n} \pi^{L}, \sigma\right)\right)$. Conditional on Firms 2 to $n$ having sold zero in periods 1 and 2 and on Firm 1 having made nonzero sales in period 1 (which happens with probability greater than $\left(1-\pi^{B}\right)\left(1-\pi^{B}-\pi^{L}\right)$ if Firm 1 deviated in the first two periods), if Firm 1 sets price $p_{3}^{\text {dev }}$ in period 3 , this price is lower than all other firms' prices with probability greater than $1-\lambda_{1} g_{3}$, yielding an expected profit greater than $(V-c)\left(1-g_{3}\right)\left(1-\lambda_{1} g_{3}\right)\left(1-\pi^{B}\right)$.

Step 6 . The period 2 prices set by a firm observing its period 1 sales belonged to $\left(0, \frac{S_{\max }}{n}\right)$, according to $E q *$.

For each $Q \in\left(0, \frac{S_{\max }}{n}\right)$ let $p_{2}^{*}(Q)$ denote the equilibrium price set in period 2 by a firm observing that it sold $Q$ in period 1 . uch that a firm having sold $Q$ in period 1. We define the set $S^{\prime}$ as follows: $S^{\prime}=\left\{Q\right.$ s.t. $Q \in\left(0, \frac{S_{\max }}{n}\right)$ and $\left.p_{2}^{*}(Q)>V\right\}$. With probability $\left(1-\pi^{B}\right) \mu^{N}\left(n S^{\prime}\right)$ (with $n S^{\prime}$ denoting the set of all elements of $S^{\prime}$ multiplied by $n$ ), demand is normal and each firm sells some $Q \in S^{\prime}$ in period 1, implying that all firms set a price strictly above $V$ in period 2, leading to expected period 2 profits smaller than or equal to $\pi^{B}(V-c) D(1+u)$. Step 1 implies therefore that $1-\alpha_{2}\left(\left(1-\pi^{B}\right) \mu^{N}\left(n S^{\prime}\right), \sigma\right)<\pi^{B}(V-c) D(1+u)$, or, after rearranging terms, $\mu^{N}\left(n S^{\prime}\right)<\frac{\sigma+\pi^{B} u}{\left(1-\pi^{B}\right)\left(1-\pi^{B}(1+u)\right) \delta}$, which implies $\mu^{N}\left(S^{\prime}\right)<$ $\lambda_{2} \frac{\sigma+\pi^{B} u}{\left(1-\pi^{B}\right)\left(1-\pi^{B}(1+u)\right) \delta}$.

Step 7. The probability, according to $E q *$, that Firm 1's sales belong to $\left(0, \frac{\overline{S_{\max }}}{n}\right) \backslash S^{\prime}$ in period 1 and to $\left(0, S_{\max }\right)$ in period 2 while all other firms sell zero in periods 1 and 2 . According to $E q *$, the probability that Firm 1's period 1 sales belong to $\left(0, \frac{S_{\max }}{n}\right) \backslash S^{\prime}$ whereas all other firms' period 1 sales are zero is $\frac{\pi^{B}}{n}\left(1-\mu^{B}\left(S^{\prime}\right)-\mu^{B}\left(\frac{S_{\max }}{n}, S_{\max }\right)\right)$. If Firm 1's period 1 sales belong to $\left(0, \frac{S_{\max }}{n}\right) \backslash S^{\prime}$ whereas all other firms' period 1 sales are zero, then according to $E q *$, in period 2 Firm 1 sets a price $p_{2}^{*}(Q) \leq V$ and all other firms set a price $p_{2}^{*}(0)>(V-c)\left(1-g_{2}\right)+c$ (by Step 4$)$, so that $p_{2}^{*}(Q)-$ $p_{2}^{*}(0)<(V-c) g_{2}$, implying that the entirety of period 2 demand goes to Firm 1 if demand is biased in Firm 1's favor and consumers' valuation $v$ of Firm 1 's product is such that $\frac{v-c}{V-c}-1>g_{2}$, which is the case with probability $\frac{\pi^{B}}{n} \nu\left(\left((V-c)\left(1+g_{2}\right)+c, V^{\prime}\right)\right)=\frac{\pi^{B}}{n}\left(1-\frac{g_{2}}{u}\right)$ if $g_{2}<u$, or $\frac{\sigma+\pi^{B} u}{\pi^{L}(1-\delta) \delta}<u$. From 
here onwards, we assume that $\frac{\pi^{B}}{\pi^{L}}$ is small and we consider values of $\sigma$ that are small relative to $u$, so that $g_{2}<u$. The probability according to $E q *$ that firms other than Firm 1 sell zero in the first and the second period whereas Firm 1 's sales in these periods belong respectively to $\left(0, \frac{S_{\max }}{n}\right) \backslash S^{\prime}$ and $\left(0, S_{\max }\right)$ is thus greater than $\left(\frac{\pi^{B}}{n}\right)^{2}\left(1-\mu^{B}\left(S^{\prime}\right)-\mu^{B}\left(\frac{S_{\max }}{n}, S_{\max }\right)\right)\left(1-\frac{g_{2}}{u}\right) . \mu^{B}\left(S^{\prime}\right)<$ $\lambda_{1} \mu^{N}\left(S^{\prime}\right)$ so that (using the results of Step 6) the latter expression is greater than $\left(\frac{\pi^{B}}{n}\right)^{2}\left(1-\lambda_{1} \lambda_{2} \frac{\sigma+\pi^{B} u}{\left(1-\pi^{B}\right)\left(1-\pi^{B}(1+u)\right) \delta}-A\right)\left(1-\frac{g_{2}}{u}\right)$.

Step 8. The period 4 prices set by all other firms after having sold zero in periods 1 to 3 and observing that Firm 1's sales belong to $\left(0, \frac{S_{\max }}{n}\right) \backslash S^{\prime}$ in period 1 and $\left(0, S_{\max }\right)$ in period 2. The probability, according to $E q *$, that Firms 2 to $n$ sell zero in periods 1, 2 and 3, while Firm 1 makes nonzero sales in periods 1 and 2 , and its period 1 sales belong to $\left(0, \frac{S_{\max }}{n}\right) \backslash S^{\prime}$, is greater than the latter lower bound times $\pi^{L}$. Define

$g_{4}=g\left(\alpha_{4}\left(\pi_{L}\left(\frac{\pi^{B}}{n}\right)^{2}\left(1-\lambda_{1} \lambda_{2} \frac{\sigma+\pi^{B} u}{\left(1-\pi^{B}\right)\left(1-\pi^{B}(1+u)\right) \delta}-A\right)\left(1-\frac{g_{2}}{u}\right), \sigma\right)\right)$.

Step 2 implies that conditional on Firm 1 having nonzero sales in periods 1 and 2 (belonging to $\left(0, \frac{S_{\max }}{n}\right) \backslash S^{\prime}$ in period 1$)$ and other firms having zero sales in periods 1 to 3 , then with probability greater than $1-g_{4}$, Firms 2 to $n$ set a price that is greater than $p_{4}^{\text {dev }}=c+(V-c)\left(1-g_{4}\right)$. Notice that the probability that after Firm 1 deviated by setting prices $p_{i}^{\text {dev }}$ in period $i(i=1,2,3)$, its sales belonged to $\left(0, \frac{S_{\max }}{n}\right) \backslash S^{\prime}$ in period 1 and $\left(0, S_{\max }\right)$ in period 2 while other firms sold zero in periods 1 to 3 is greater than $\left(1-\mu^{N}\left(S^{\prime}\right)-\mu^{N}\left(\frac{S_{\max }}{n}, S_{\max }\right)-\frac{\pi^{L}}{1-\pi^{B}}\right)\left(1-\pi^{B}\right)^{3}$, which is greater than $\left(1-\lambda_{2} \frac{\sigma+\pi^{B} u}{\left(1-\pi^{B}\right)\left(1-\pi^{B}(1+u)\right) \delta}-A-\frac{\pi^{L}}{1-\pi^{B}}\right)\left(1-\pi^{B}\right)^{3}$.

Step 9. Firm 1's possible deviations in periods 1 to 4 and the corresponding expected profits. Steps 1 to 8 imply that if Firm 1 sets price $p_{i}^{\text {dev }}$ in period $i(i=$ $1,2,3,4)$ then its expected profit is at least $(V-c) D\left(1-g_{1}\right)\left(1-\pi^{B}\right)$ in period $1,(V-c) D\left(1-g_{2}\right)\left(1-\pi^{B}\right)^{2}$ in period $2,(V-c) D\left(1-\lambda_{1} g_{3}\right)\left(1-g_{3}\right)\left(1-\pi^{B}-\pi^{L}\right)\left(1-\pi^{B}\right)^{2}$ in period 3 and $(V-c) D\left(1-\lambda_{2} \frac{\sigma+\pi^{B} u}{\left(1-\pi^{B}\right)\left(1-\pi^{B}(1+u)\right) \delta}-A-\frac{\pi^{L}}{1-\pi^{B}}\right)\left(1-\pi^{B}\right)^{4}\left(1-g_{4}\right)^{2}$ in period 4.

Step 10. (1) implies the existence of a profitable deviation. Assume that inequality (1) holds: $1+\delta+\delta^{2}+(1-A) \delta^{3}>\frac{1}{n(1-\delta)} \cdot(1)$ is equivalent to $\delta^{4}+A \delta^{3}<1-\frac{1}{n}$, which provides a strictly positive lower bound on the possible values of $\frac{1}{1-\delta}$. If $\pi^{L}, \pi^{B}, \frac{\pi^{B} u}{\pi^{L}}, \frac{n u}{(1-\delta) \delta^{3} \pi^{B} \pi^{L}(1-A)}$ and $\sigma$ are close to zero, then $g_{1}, g_{2}, g_{3}$, and $g_{4}$ are close to zero, each $p_{i}^{\text {dev }}(i=1,2,3,4)$ is close to $V$, and 
with a probability close to 1 in periods 1 to 3 , and close to $1-A$ in period 4 , a firm that sets price $p_{i}^{d e v}$ in period $i(i=1,2,3,4)$ serves the entire demand in each of the first four periods. Such a deviation yields an expected profit that is close to $(V-c) D\left(1+\delta+\delta^{2}+(1-A) \delta^{3}\right)$. If $1+\delta+\delta^{2}+(1-A) \delta^{3}>\frac{1}{n(1-\delta)}$ and $\pi^{B} u$ is close to zero (which follows from $\frac{\pi^{B}}{\pi^{L}}$ and $\frac{n u}{(1-\delta) \delta^{3} \pi^{B} \pi^{L}(1-A)}$ being close to zero), then this is greater than a firm's expected profit according to $E q *$, which cannot exceed $\frac{(V-c) D\left(1+\pi^{B} u\right)}{n(1-\delta)}$.

Proof of Proposition 5. Preamble: the parameters of the price war. We assume that condition (2) holds (which implies $\delta>\frac{1}{2}$ ), and that $\pi^{B}, \pi^{L}$ and $u$ are close to zero, and $c>5\left(V^{\prime}-V\right.$ ) (which is true if $u$ is small enough relative to $c / V$ ). We want to find a price war level and a price war duration such that (i) any firm's expectation of the sum of its future discounted profits at the start of a price war's first period is 0 if all firms are expected to follow the strategies described in Section 3.3 (that is, those described in Section 2.2 with the difference that in a correction period, the targeted firm sets price $V^{\prime}+1$ ) and (ii) these strategies cannot be individually improved upon. Let $P W_{r}\left(p, k^{\prime}\right)$ denote a firm's expectation of the discounted sum of its future payoffs at the start of the $r$-th period of a price war lasting $k^{\prime}$ periods $\left(1 \leq r \leq k^{\prime}\right)$ with a price level of $p(p<V)$, assuming all firms act according to the candidate equilibrium. The price war strategies and transition rules described above imply that at the beginning of the $r$-th period of a price war lasting a total of $k^{\prime}$ periods, each firm's current period expected profit is $\frac{(p-c) D}{n}$, and with probability $\left(\pi^{B}+\pi^{L}\right)$, the state of the world in the next period is the first period of a price war, whereas with probability $1-\left(\pi^{B}+\pi^{L}\right)$, it is ' $(r+1)$-th period of a price war' if $r<k^{\prime}$ and 'normal collusion' if $r=k^{\prime}$. This implies the following equalities:

$$
\begin{aligned}
P W_{r}\left(p, k^{\prime}\right) & =\frac{(p-c) D}{n}+\delta\left(1-\pi^{B}-\pi^{L}\right) P W_{r+1}\left(p, k^{\prime}\right)+\delta\left(\pi^{B}+\pi^{L}\right) P W_{1}\left(p, k^{\prime}\right) \text { if } r<k^{\prime} \\
P W_{k^{\prime}}\left(p, k^{\prime}\right) & =\frac{(p-c) D}{n}+\delta\left(1-\pi^{B}-\pi^{L}\right) \frac{(V-c) D}{n(1-\delta)}+\delta\left(\pi^{B}+\pi^{L}\right) P W_{1}\left(p, k^{\prime}\right),
\end{aligned}
$$


implying

$$
\begin{aligned}
P W_{1}\left(p, k^{\prime}\right) & =\frac{(p-c) D}{n} \sum_{1 \leq t \leq k^{\prime}}\left(\delta\left(1-\pi^{B}-\pi^{L}\right)\right)^{t} \\
& +\delta\left(\pi^{B}+\pi^{L}\right) P W_{1}\left(p, k^{\prime}\right) \sum_{1 \leq t \leq k^{\prime}}\left(\delta\left(1-\pi^{B}-\pi^{L}\right)\right)^{t-1} \\
& +\left(\delta\left(1-\pi^{B}-\pi^{L}\right)\right)^{k^{\prime}} \frac{(V-c) D}{n(1-\delta)}
\end{aligned}
$$

or equivalently

$$
\begin{array}{r}
P W_{1}\left(p, k^{\prime}\right)\left(1-\delta\left(\pi^{B}+\pi^{L}\right) \frac{\left(1-\left(\delta\left(1-\pi^{B}-\pi^{L}\right)\right)^{k^{\prime}}\right)}{1-\delta\left(1-\pi^{B}-\pi^{L}\right)}\right) \\
=\frac{(p-c) D}{n} \frac{\left(1-\left(\delta\left(1-\pi^{B}-\pi^{L}\right)\right)^{k^{\prime}}\right)}{1-\delta\left(1-\pi^{B}-\pi^{L}\right)}+\frac{(V-c) D}{n(1-\delta)}\left(\delta\left(1-\pi^{B}-\pi^{L}\right)\right)^{k^{\prime}} .
\end{array}
$$

Let $F\left(p, k^{\prime}\right)$ denote the right-hand side of this equation, multiplied by $n / D$ :

$$
F(p, \kappa)=\frac{(p-c)\left(1-\left(\delta\left(1-\pi^{B}-\pi^{L}\right)\right)^{\kappa}\right)}{1-\delta\left(1-\pi^{B}-\pi^{L}\right)}+\frac{(V-c)\left(\delta\left(1-\pi^{B}-\pi^{L}\right)\right)^{\kappa}}{(1-\delta)}
$$

If $\delta>\frac{1}{2}$, and $\pi^{B}, \pi^{L}$ and $u$ are close enough to zero, then $F\left(c-\left(V^{\prime}-V\right), 1\right)>$ 0 . Also, $\operatorname{Lim}_{\kappa \rightarrow \infty} F\left(c-\left(V^{\prime}-V\right), \kappa\right)<0$. Therefore, if $\delta>\frac{1}{2}$ and $\pi^{B}, \pi^{L}$ and $u$ are close enough to zero, there exists an integer $k^{\prime} \geq 1$ such that $F\left(c-\left(V^{\prime}-V\right), k^{\prime}+1\right)<$ $0<F\left(c-\left(V^{\prime}-V\right), k^{\prime}\right)$. We show now that $F\left(c-5\left(V^{\prime}-V\right), k^{\prime}\right)<0$.

$$
\begin{gathered}
F\left(c-5\left(V^{\prime}-V\right), k^{\prime}\right)<0 \\
\Longleftrightarrow \frac{5\left(V^{\prime}-V\right)\left(1-\left(\delta\left(1-\pi^{B}-\pi^{L}\right)\right)^{k^{\prime}}\right)}{1-\delta\left(1-\pi^{B}-\pi^{L}\right)}>\frac{(V-c)\left(\delta\left(1-\pi^{B}-\pi^{L}\right)\right)^{k^{\prime}}}{(1-\delta)} .
\end{gathered}
$$


But

$$
\begin{gathered}
F\left(c-\left(V^{\prime}-V\right), k^{\prime}+1\right)<0 \\
\Longleftrightarrow \frac{\left(V^{\prime}-V\right)\left(1-\left(\delta\left(1-\pi^{B}-\pi^{L}\right)\right)^{k^{\prime}+1}\right)}{1-\delta\left(1-\pi^{B}-\pi^{L}\right)}>\frac{(V-c)\left(\delta\left(1-\pi^{B}-\pi^{L}\right)\right)^{k^{\prime}+1}}{(1-\delta)} \\
\Rightarrow \frac{5\left(V^{\prime}-V\right)\left(1-\left(\delta\left(1-\pi^{B}-\pi^{L}\right)\right)^{k^{\prime}}\right)(1-\delta)}{(V-c)\left(\delta\left(1-\pi^{B}-\pi^{L}\right)\right)^{k^{\prime}}\left(1-\delta\left(1-\pi^{B}-\pi^{L}\right)\right)}>5 \delta\left(1-\pi^{B}-\pi^{L}\right) \frac{1-\left(\delta\left(1-\pi^{B}-\pi^{L}\right)\right)^{k^{\prime}}}{1-\left(\delta\left(1-\pi^{B}-\pi^{L}\right)\right)^{k^{\prime}+1}} \\
>\frac{5 \delta\left(1-\pi^{B}-\pi^{L}\right)}{1+\left(\delta\left(1-\pi^{B}-\pi^{L}\right)\right)^{k^{\prime}}},
\end{gathered}
$$

which is greater than 1 if $\delta>\frac{1}{2}$ and $\pi^{B}, \pi^{L}$ are both close to zero, implying that $F\left(c-5\left(V^{\prime}-V\right), k^{\prime}\right)<0$. By continuity, there exists some price $p^{w}$ between $c-5\left(V^{\prime}-V\right)$ and $c-\left(V^{\prime}-V\right)$ such that $P W_{1}\left(p^{w}, k^{\prime}\right)=F\left(p^{w}, k^{\prime}\right)=0$.

We now prove that at the beginning of any stage of a price war, it is a best response for a firm to set price $p^{w}$ and truthfully report its sales, given that all firms are expected to follow the strategies described above. First, the Bellman equation above implies that for all $r$ such that $1<r \leq k^{\prime}, P W_{r}\left(p^{w}, k^{\prime}\right)>$ $P W_{1}\left(p^{w}, k^{\prime}\right)=0$. Consider a firm at the start of the $r$-th period of a price war. Complying with the candidate equilibrium strategy yields an expectation of the sum of future discounted profits equal to $P W_{r}\left(p^{w}, k^{\prime}\right) \geq 0$. Let $B R_{r}\left(p^{w}, k^{\prime}\right) \geq 0$ denote the expectation of the sum of future discounted profits of a firm (say, Firm 1) at the beginning of the $r$-th period of a price war, assuming that the firm, from period 1 onwards, maximizes the expectation of the discounted sum of its future profits, and that all other firms act according to the candidate equilibrium. First, notice that at the beginning of any price war period, a firm cannot earn a strictly positive profit: this would require a positive margin, hence a price above $c$ and therefore greater than $p^{w}+\left(V^{\prime}-V\right)$, implying zero sales even if demand were biased in favor of the deviating firm. Second, if Firm 1 sets a price different from $p^{w}$, then with probability 1 , the state of the world in the next period is 'first period of a price war'. This is because when not all firms set the same price, it is impossible that all firms have identical nonzero sales. Two cases must be distinguished. If one or several of the other firms sell(s) zero, at least one sales report is zero, which causes the next period to be the first period of a price war. If all firms other than Firm 1 have nonzero sales, then Firm 1 has zero sales with probability 1 and whatever its sales report, it is different from the other firms' with probability 1 since Firm 1 cannot 'guess' the value 
of other firms' sales (the distribution of demand levels is atomless if demand is nonzero). Therefore, whatever Firm 1's announcement after deviating, with probability 1 it is not the case that all firms report identical nonzero sales. Therefore the next period is the first period of a price war. This implies the following inequality: $B R_{1}\left(p^{w}, k^{\prime}\right) \leq \delta B R_{1}\left(p^{w}, k^{\prime}\right)$ implying $B R_{1}\left(p^{w}, k^{\prime}\right) \leq 0$ and therefore $B R_{1}\left(p^{w}, k^{\prime}\right)=0$. It is therefore a best response in period 1 to set a price equal to $p^{w}$. If the best response in the $r$-th period of a price war $(r>1)$ involved a price different from $p^{w}$, then the above analysis implies that the inequality $B R_{r}\left(p^{w}, k^{\prime}\right) \leq \delta B R_{1}\left(p^{w}, k^{\prime}\right)=0<B R_{r}\left(p^{w}, k^{\prime}\right)$, which is a contradiction. Therefore, the price war as described above is indeed an equilibrium. The price war mentioned in the remainder of this proof is the one described above, with $P W_{1}\left(p^{w}, k^{\prime}\right)=0$.

Step 1: the expected sum of future discounted profits for a firm according to the state of the game. Let $W_{c, r}, W_{c-, r}$ and $W$ denote the expected sum of a firm's future discounted profits at the beginning of, respectively, a correction period at its own expense with $r$ remaining periods $(1 \leq r \leq k)$, a correction period at another firm's expense with $r$ remaining periods, and a normal collusion period (assuming that all firms behave according to the candidate equilibrium). Since, at the beginning of a normal collusion period, the distribution of future sales is symmetric across firms, and along any equilibrium path total expected profits add up to $(V-c) D$, it follows that $W=\frac{(V-c) D}{n(1-\delta)}$. Also, since ahead of any period along any equilibrium path, $n$ or $(n-1)$ firms are in a symmetric situation, $W_{c-, r} \leq \frac{(V-c) D}{(n-1)(1-\delta)}$.

In any correction period, there is a probability $\frac{(n-1) \pi^{B}}{n}$ that one of the non-targeted firms will benefit from biased demand, implying that in the following period, the expected sum of the previously targeted firm' future flow of discounted profits will be $W_{c-, k}$. This implies that for any $r$ between 1 and $k, W_{c, r}=\delta\left[\left(1-\frac{(n-1) \pi^{B}}{n}\right) W_{c, r-1}+\frac{(n-1) \pi^{B}}{n} W_{c-, k}\right]$ (with the notation $\left.W_{c, 0}=W\right)$. These equalities imply that for any $r$ between 1 and $k$,

$W_{c, r}=\delta^{r}\left(1-\frac{(n-1) \pi^{B}}{n}\right)^{r} W+\frac{\frac{\delta(n-1) \pi^{B}}{n}}{1-\delta\left(1-\frac{(n-1) \pi^{B}}{n}\right)}\left[1-\delta^{r}\left(1-\frac{(n-1) \pi^{B}}{n}\right)^{r}\right] W_{c-, k}$

The above results imply that for any number of firms $n \geq 2$, the following 
inequalities hold:

$\frac{\delta^{r}(V-c) D}{(1-\delta) n}\left(1-\frac{(n-1) \pi^{B}}{n}\right)^{r} \leq W_{c, r} \leq \frac{\delta^{r}(V-c) D}{(1-\delta) n}\left(1-\frac{(n-1) \pi^{B}}{n}\right)^{r}+\frac{\delta \pi^{B}(V-c) D}{n(1-\delta)^{2}}$

We prove now that for any $r(1 \leq r \leq k), W_{c, r} \leq W \leq W_{c-, r}$. First, the above Bellman equations characterizing each $W_{c, r}$ imply, by induction, that either for all $r, W_{c, r} \leq W$, or for all $r, W_{c, r} \geq W$. Assume (by contradiction) that $W_{c, k}>W$. Since expected profits add up to $(V-c) D$ ahead of any period in the candidate equilibrium, the equality $W_{c, k}+(n-1) W_{c-, k}=n W$ holds, implying that $W_{c-, k}<W$. But this inequality, together with the Bellman equation characterizing $W_{c, 1}$ implies that $W_{c, 1}<W$, which is a contradiction.

Finally, notice that the inequality $W_{c, r} \leq W$ implies that for any $r(2 \leq r \leq$ $k), W_{c, r+1} \leq W_{c, r}$ and $W_{c-, r+1} \geq W_{c-, r}$.

Step 2. Whatever the state of the world at the beginning of period $t$, if Firm $i$ complied with the strategies prescribed by the candidate equilibrium in all previous periods and it assumes that all other firms behave according to the candidate equilibrium, and Firm $i$ did set a price at the beginning of period $t$ in accordance with the candidate equilibrium, or the observation of its own sales combined with the knowledge of the price it set at the beginning of the period allows it to know that the distribution of current period sales, when observed at the end of the following period, will not reveal any deviation, then reporting sales truthfully is a best response for Firm $i$.

Proof. Since misreporting at the end of period $t$ is detected at the latest at the end of period $(t+1)$, leading to a price war from period $(t+2)$ onwards, and expected per-period profits cannot exceed total profits $(V-c) D\left(1+\pi^{B} u\right)$, misreporting would allow Firm $i$ to earn at most $(V-c) D\left(1+\pi^{B} u\right)$ in period $(t+1)$ and an expected discounted sum of subsequent profits equal to 0 . In contrast, complying with the strategy prescribed by the candidate equilibrium would lead, at the beginning of period $(t+1)$, to an expected sum of future discounted profits greater than or equal to $W_{c, k}$. Since (4) implies the inequality $W_{c, r} \geq(V-c) D\left(1+\pi^{B} u\right)$ for all $r$ if $\pi^{B}$ and $u$ are close enough to zero (in which case it boils down to $\delta^{k} \geq n(1-\delta)$ ), truthful sales reporting is a best response for a firm that behaved as prescribed by the candidate equilibrium.

Step 3. Notation: $D_{t}$ denotes total demand in period $t$. At the beginning of a correction period, it is a best response for all firms to set the price prescribed by the candidate equilibrium.

Proof. Assume the state of the game at the beginning of period $t$ is 'cor- 
rection at the expense of Firm 1 (without loss of generality), with $r$ remaining periods'. We prove first that it is optimal for Firm 1 to behave as prescribed by the candidate equilibrium, that is, by setting $p_{t}^{1}=V^{\prime}+1$ and truthfully reporting its zero sales. We showed in Step 2 of this proof that conditional of setting a price equal to $V^{\prime}+1$ it is optimal for Firm 1 to truthfully report its zero sales. Assume that Firm 1 sets a price $p_{t}^{1} \neq V^{\prime}+1$. Any price greater than $V^{\prime}$ yields the same zero profits as the equilibrium strategy in period $t$ and the same information to other firms. Therefore, such prices lead to exactly the same payoff distribution for Firm 1 in period $t$ and subsequent periods as $p_{t}^{1}=V^{\prime}+1$. Consider now a price $p \in\left(V, V^{\prime}\right)$. Such a price leads to exactly the same outcome as $p_{t}^{1}=V^{\prime}+1$ unless demand is biased in favor of Firm 1 , with a valuation $v \geq p$. In this latter case, if Firm 1 sets $p_{t}^{1}=V^{\prime}+1$, it earns zero in period $t$ and, since its best response is then to truthfully report its zero sales (as proved in Step 2), its expected sum of future profits is at least $\delta W_{c, r-1}$ (this is the expected sum is Firm 1 plans to comply with the candidate equilibrium strategies in the future, which Firm 1 can do); whereas if it sets $p_{t}^{1}=p$, its deviation will be detected at the end of the following period, leading to profits below $(V-c) D\left[(1+\delta)\left(1+\pi^{B} u\right)\right]$. (2) implies the inequality $\delta W_{c, r-1}>(V-c) D\left[\left(1+\delta\left(1+\pi^{B} u\right)\right]\right.$ if $\pi^{B}$ and $u$ are close enough to zero (in which case it boils down to $\delta^{k} \geq n\left(1-\delta^{2}\right)$ ), making such a deviation unprofitable. Consider now a price $p \leq V$. Unless demand is zero or biased, setting such a price leads Firm 1 to being 'exposed' after two periods at most. The corresponding expected sum of future discounted profits is thus less than $(V-c) D\left(1+\pi^{B} u\right)\left[(1+\delta)+\left(\pi^{L}+\pi^{B}\right)\right]$. If $\pi^{B}, \pi^{L}$ and $u$ are close enough to zero, (2) implies that this expression is less than $W_{c, k}$, that is, less than $W_{c, r}$ for any $r \leq k$. Therefore, it is optimal for Firm 1 to follow the strategy prescribed by the candidate equilibrium, which yields it an expected sum of future discounted profits equal to $W_{c, r}$.

Consider now a firm other than Firm 1, say, Firm 2 (without loss of generality). Complying with the actions prescribed by the candidate equilibrium leads for Firm 2 to an expected sum of future discounted profits equal to $W_{c-, r}$. Assume now that Firm 2 deviates and sets a price $p_{t}^{2} \neq V$. If $p_{t}^{2}>V$, then Firm 2 earns zero in period $t$ and whatever it reports at the end of period $t$, its deviation is detected at the end of period $(t+1)$ unless demand in period $t$ is zero, because a distribution of sales such that total sales are nonzero while two firms (Firms 1 and 2) have zero sales is incompatible with equilibrium. This, together with the fact that a firm's per-period expected profit cannot exceed 
$(V-c) D\left(1+\pi^{B} u\right)$, implies that the corresponding expected sum of future discounted profits is less than or equal to $(V-c) D\left(1+\pi^{B} u\right)\left[\delta+\frac{\pi^{L} \delta^{2}}{1-\delta}\right]$. If $\pi^{B}$, $\pi^{L}$ and $u$ are close enough to zero, (3) implies that this expression is less than $W_{c, k}$, and therefore less than $W_{c-, r}$. A price $p_{t}^{2}>V$ therefore cannot improve upon the behavior prescribed by the candidate equilibrium for Firm 2 .

Consider now the possibility of a price $p_{t}^{2}<V$. Such a price would yield Firm 2 at most $(V-c) D$ in expectation in period $t$. If $D_{t}=0$, which happens with probability $\pi^{L}$, period $t$ sales are identical to what they would be absent a deviation by Firm 2. Therefore, as shown in Step 2, it would be optimal for Firm 2 in this case to report zero sales, leading in period $(t+1)$ to either 'normal collusion' (if $r=1$ ) or to 'correction at the expense of Firm 1, with $(r-1)$ remaining periods' (if $r \geq 2$ ). This would lead at the beginning of period $(t+1)$ to an expected sum of future discounted profits equal to $W_{c-, r-1}$ (with the slight abuse of notation $W_{c-, 0}=W$ ). If demand is normal, a deviation leads to a sales profile that is compatible with equilibrium behavior (with demand biased in favor of Firm 2). As shown in Step 2, it is then optimal for Firm 2 to truthfully reveal its sales, leading at the beginning of period $(t+1)$ to an expected sum of future discounted profits equal to $W_{c, k}$. Finally, if demand is biased, then with probability 1 one of the firms (Firm 2 or another one) serves the entire demand, leading to an expected sum of future discounted profits below $W_{c-, k}$. Therefore, a deviation with $p_{t}^{2}<V$ would lead at the beginning of period $t$ to an expected sum of Firm 2's future discounted profits less than or equal to $(V-c) D+\delta\left(\pi^{L} W_{c-, r-1}+\left(\left(1-\pi^{B}\right)-\pi^{L}\right) W_{c, k}+\pi^{B} W_{c-, k}\right)$, whereas in the absence of deviation this expected sum is equal to $W_{c-, r}$. The difference between this expected sum in the absence and in the presence of such a deviation is thus greater than or equal to

$$
\begin{aligned}
& W_{c-, r}-(V-c) D-\delta\left(\pi^{L} W_{c-, r-1}-\left(\left(1-\pi^{B}\right)-\pi^{L}\right) W_{c, k}+\pi^{B} W_{c-, k}\right) \\
& =\quad W+\delta \pi^{L}\left(W_{c-, r}-W_{c, r-1}\right)+\left(1-\delta \pi^{L}\right)\left(W_{c-, r}-W\right)- \\
& -(V-c) D-\delta\left(\pi^{L} W^{\prime}-\left(\left(1-\pi^{B}\right)-\pi^{L}\right) W_{c, k}+\pi^{B} W_{c-, k}\right) \\
& \geq \quad W-(V-c) D-\delta\left(\pi^{L} W+\left(\left(1-\pi^{B}\right)-\pi^{L}\right) W_{c, k}+\pi^{B} W_{c-, k}\right) \\
& \geq \quad W-(V-c) D\left[1+\delta\left(\left(1-\pi^{B}\right) \frac{W_{c, k}}{(V-c) D}+\frac{\pi^{B}}{(n-1)(1-\delta)}\right)\right] \\
& \geq \quad \frac{(V-c) D}{n(1-\delta)}-(V-c) D\left[1+\delta\left(1-\pi^{B}\right) \frac{\delta^{k}}{n(1-\delta)}\right] \\
& -(V-c) D\left[\delta\left(\left(1-\pi^{B}\right) \frac{\delta \pi^{B}}{n(1-\delta)^{2}}+\frac{\pi^{B}}{(n-1)(1-\delta)}\right)\right]
\end{aligned}
$$

If $\pi^{B}$ is close enough to zero, condition (2) implies that this difference is positive, so that it is a best response for Firm 2 to follow the strategy prescribed by the candidate equilibrium.

Step 4. If the state of the world at the beginning of period $t$ is 'normal collu- 
sion' and all firms followed the strategy prescribed by the candidate equilibrium in all previous periods, then it is a best response for Firm 1 (without loss of generality) to set $p_{t}^{1}=V$.

Proof. Consider a subgame starting in period $t$, such that the state of the game at the beginning of period $t$ is 'normal collusion' and all firms followed the strategy prescribed by the candidate equilibrium in all previous periods. Firm 1 's expected sum of future discounted profits is $W$ if it sets price as prescribed by the candidate equilibrium (that is, $p_{t}^{1}=V$ ).

We prove hereafter that, if conditions (2)-(3) hold, then in a 'normal collusion' period, neither setting a price $p_{t}^{1}<V$ nor setting one such that $p_{t}^{1}>V$ leads to an expected sum of future discounted profits strictly greater than $W$. We prove this by contradiction.

We assume that there exists a best response such that, with a positive probability, Firm 1 sets a price $p_{t}^{1}<V$ in some 'normal collusion' state. Let $W^{\prime}$ denote Firm 1's expected sum of future discounted profits at the beginning of any such 'normal collusion' state, given this best response. Since all possible best responses must yield the same expected sum of future discounted profits at the beginning of any 'normal collusion' period, $W^{\prime}$ is also equal to Firm 1's expected sum of future discounted profits at the beginning of any subsequent 'normal collusion' period.

In period $t$, setting a price $p_{t}^{1}<V$ allows Firm 1 to serve the entire demand unless demand is biased in favor of some other firm, with a bias strong enough to offset the price difference between that firm and Firm 1. If $D_{t}=0$, then the state of the world is 'normal collusion' again in period $(t+1)$, leading to an expected sum of future discounted profits equal to $W^{\prime}$ at the beginning of period $(t+1)$. If demand is biased, then with probability 1 one of the firms (Firm 1 or another one) serves the entire demand, leading to an expected sum of future discounted profits below $W_{c-, k}$. If demand is normal and nonzero, the state of the world at the beginning of period $(t+1)$ is 'correction at the expense of Firm 1 , with $k$ remaining periods', leading to an expected sum of future discounted profits of $W_{c, k}$ (by Step 2). Therefore, a deviation with $p_{t}^{1}<V$ would lead at the beginning of period $t$ to an expected sum of future discounted profits less than or equal to $(V-c) D+\delta\left(\pi^{L} W^{\prime}+\pi^{B} W_{c-, k}+\left(1-\pi^{B}-\pi^{L}\right) W_{c, k}\right)$ :

$$
W^{\prime} \leq(V-c) D+\delta\left(\pi^{L} W^{\prime}++\pi^{B} W_{c-, k}+\left(1-\pi^{B}-\pi^{L}\right) W_{c, k}\right),
$$


implying

$$
\begin{aligned}
& \frac{\left(1-\pi^{L} \delta\right) W^{\prime}}{(V-c) D} \leq 1+\delta\left(1-\pi^{B}-\pi^{L}\right) \frac{W_{c, k}}{(V-c) D}+\delta \pi^{B} \frac{W_{c-, k}}{(V-c) D} \\
\leq & 1+\delta\left(1-\pi^{B}-\pi^{L}\right)\left(\frac{\delta^{k}}{(1-\delta) n}+\frac{\delta \pi^{B}}{n(1-\delta)^{2}}\right)+\frac{\delta \pi^{B}}{(1-\delta)(n-1)}
\end{aligned}
$$

If $\pi^{B}$ and $\pi^{L}$ are close enough to zero, condition (3) implies that the right-hand term of this inequality is less than $W$, and therefore that $W^{\prime}<W$. It is thus not a best response for a firm to undercut its competitors in a normal collusion period.

We show now that there exists no best response such that, with a positive probability, $p_{t}^{1}>V$. If $p_{t}^{1}>V$ and demand is neither biased nor zero, then Firm 1 earns zero in period $t$. In this case, whatever it reports at the end of period $t$, its deviation is detected at the end of period $(t+1)$, because a distribution of sales such that total sales are nonzero while only one firm has zero sales is incompatible with equilibrium. This, together with the fact that a firm's per-period expected profit cannot exceed $(V-c) D\left(1+\pi^{B} u\right)$, implies that the corresponding expected sum of future discounted profits is less than or equal to $(V-c) D\left(1+\pi^{B} u\right)\left[\left(\frac{\pi^{B}}{n}+\delta\right)+\pi^{L} \frac{\delta^{2}}{1-\delta}\right]$. If $\pi^{B}, \pi^{L}$ and $u$ are close enough to zero, condition (2) implies that this expression is less than $W$. A price $p_{t}^{1}>V$ therefore cannot improve upon the behavior prescribed by the candidate equilibrium for Firm 1 in a 'normal collusion' period.

Step 5. The above steps imply that the strategy profile under consideration is an equilibrium strategy profile if $\pi^{B}, \pi^{L}$ and $u$ are close enough to zero, and conditions (2)-(3) are satisfied. By construction, this equilibrium is symmetric and involves only pure strategies, and along the equilibrium path, the prevailing price is $V$ in all periods with probability one.

Proof of Proposition 6. Step 1. For each $n$ between 3 and 10, one can check numerically that there exists a value of $k$ (the duration of the correction phase in the equilibria described in Section 4) and a nonempty interval of values of $\delta$ that is bounded away from 1, such that conditions (1)-(3) are satisfied with $A=0$. By continuity, (1)-(3) also hold for some small, strictly positive values of $A$. Let $A^{*}$ be one such value. The corresponding values of $k$ and $\delta$ are displayed in Figure 1 (rather than $\delta$, Figure 1 displays the equivalent discount rate $\rho$, defined by $\left.\delta=\frac{1}{1+\rho}\right)$. Let $\delta_{\min }$ and $\delta_{\max }$ denote the lower and upper bound of the set of values of $\delta$ satisfying (1)-(3) for a certain set of values of $k$ and $n$, given $A^{*}$. Notice that $\delta_{\min }>0$ and $\delta_{\max }<1$. 
Step 2. We show hereafter that for each $n$ between 3 and 10, it is possible to construct a set of stochastic demand functions satisfying the assumptions of the model, with $\pi^{L}, \pi^{B}, \frac{\pi^{B} u}{\pi^{L}}$ and $\frac{n u}{\left(1-\delta_{\max }\right) \delta_{\min }^{3} \pi^{B} \pi^{L}}$ arbitrarily close enough to zero and such that $\operatorname{Max}_{Q} \frac{\mu^{N}(Q)}{\mu^{N}(n Q)}, \operatorname{Max}_{Q} \frac{\mu^{N}(Q)}{\mu^{B}(Q)}$ and $\operatorname{Max}_{Q} \frac{\mu^{B}(Q)}{\mu^{N}(Q)}$ are bounded.

We choose some $D>0, V>0$ and $c \in(0, V)$. Let $\varepsilon$ denote a small positive number. We define $\pi^{L}(\varepsilon)=\varepsilon, \pi^{B}(\varepsilon)=\varepsilon^{2}$ and we consider a stochastic demand function defined as follows (using the definitions of 'normal' and 'biased' introduced in Section 2). With probability $\left(1-\pi^{B}(\varepsilon)\right)$ demand is normal, otherwise it is biased. We define some $R(\varepsilon), p(\varepsilon)$ and $p^{B}(\varepsilon)$ such that, conditional on demand being normal (resp. biased), demand is drawn from a distribution with (i) an atom in zero with probability $\pi^{L}(\varepsilon)$ (resp. probability zero), (ii) the uniform distribution over $(0, R(\varepsilon) D)$ with probability $1-p(\varepsilon)-\pi^{L}(\varepsilon)$ (resp. probability $1-p^{B}(\varepsilon)$ ), and (iii) with probability $p(\varepsilon)$ (resp. $p^{B}(\varepsilon)$ ) the uniform distribution over $(R(\varepsilon) D, n R(\varepsilon) D)$. For expected demand to be $D$ both in the case of normal and biased demand, and for the probability that demand exceeds $\frac{1}{n}$-th of its maximum value to be no greater than $A^{*}$ both when demand is normal and when it is biased, it is sufficient that the following equalities hold: $\left(\left(1-p(\varepsilon)-\pi^{L}(\varepsilon)\right)+(n+1) p(\varepsilon)\right) R(\varepsilon)=2$, $\left(\left(1-p^{B}(\varepsilon)\right)+(n+1) p^{B}(\varepsilon)\right) R(\varepsilon)=2, p(\varepsilon)=A^{*}$. These three identities yield $R(\varepsilon), p(\varepsilon)$ and $p^{B}(\varepsilon)$. One can check that as $\varepsilon$ goes to zero, the distributions of demand defined above, denoted $\mu_{\varepsilon}^{N}$ (for normal demand) and $\mu_{\varepsilon_{B}}^{B}$ (for biased demand) are such that $\operatorname{Max}_{Q} \frac{\mu_{\varepsilon}^{N}(Q)}{\mu_{\varepsilon}^{N}(n Q)}, \operatorname{Max}_{Q} \frac{\mu_{\varepsilon}^{N}(Q)}{\mu_{\varepsilon}^{B}(Q)}$ and $\operatorname{Max}_{Q} \frac{\mu_{\varepsilon}^{B}(Q)}{\mu_{\varepsilon}^{N}(Q)}$ remain bounded: they respectively converge towards $\operatorname{Max}\left(\frac{1-A^{*}}{n A^{*}}, 1\right), 1$ and 1 as $\varepsilon$ converges towards zero.

Finally, we define $u(\varepsilon)$ by the identity $\frac{n u(\varepsilon)}{\left(1-\delta_{\max }\right) \delta_{\min }^{3} \pi^{B} \pi^{L}(1-A)}=\varepsilon$. This demand function satisfies all the assumptions of the model, and it is such that $\pi^{L}, \pi^{B}, \frac{\pi^{B} u}{\pi^{L}}$ and $\frac{n u}{(1-\delta) \delta^{3} \pi^{B} \pi^{L}(1-A)}$ are all smaller than or equal to $\varepsilon$.

\section{References}

[1] Abreu, Dilip, Paul Milgrom, and David Pearce, 1991, Information and timing in repeated partnerships, Econometrica 59(6), 1713-1733.

[2] Acemoglu, Daron, Kostas Bimpikis, and Asuman Ozdaglar, 2009, Price and capacity competition, Games and Economic Behavior 66(1), 1-26. 
[3] Aoyagi, Masaki, 2002, Collusion in dynamic Bertrand oligopoly with correlated private signals and communication, Journal of Economic Theory 102, 229-248.

[4] Aoyagi, Masaki, 2007, Efficient collusion in repeated auctions with communication, Journal of Economic Theory 134, 61-92.

[5] Athey, Susan, and Kyle Bagwell, 2001, Optimal collusion with private information, The RAND Journal of Economics 32(3), 428-465.

[6] Athey, Susan, and Kyle Bagwell, 2008, Collusion with persistent cost shocks, Econometrica 76(3), 493-540.

[7] Athey, Susan, Kyle Bagwell, and Chris Sanchirico, 2004, Collusion and price rigidity, The Review of Economic Studies 71(2), 317-349.

[8] Awaya, Yu, and V. Krishna, 2016, On Communication and Collusion, American Economic Review, 106(2), 285-315.

[9] Awaya, Yu, and V. Krishna, 2019, Communication and Cooperation in Repeated Games, Theoretical Economics, 14(2), 513-553.

[10] Awaya, Yu, and V. Krishna, 2020, Information Exchange in Cartels, Rand Journal of Economics, 51(2), 421-446.

[11] Carlton, Dennis, Robert Gertner, and Andrew Rosenfield, 1997, Communication among Competitors: Game Theory and Antitrust Application of Game Theory to Antitrust, George Mason Law Review 5(3), 423-440.

[12] Chan, Jimmy, and Wenzhang Zhang, 2015, Collusion enforcement with private information and private monitoring, Journal of Economic Theory, $157,188-211$.

[13] Compte, Olivier, 1998, Communication in repeated games with imperfect private monitoring, Econometrica 66(3), 597-626.

[14] Fudenberg, Drew, Yuhta Ishii, and Scott Duke Kominers, 2014, DelayedResponse Strategies in Repeated Games with Observation Lags, Journal of Economic Theory 150, 487-514.

[15] Gentzkow, Matthew, and Emir Kamenica, 2017, Disclosure of Endogenous Information, Economic Theory Bulletin 5(1), 47-56. 
[16] Green, Edward J., and Robert H. Porter, 1984, Noncooperative collusion under imperfect price information, Econometrica 52(1), 87-100.

[17] Harrington, Joseph E., 2006, How Do Cartels Operate?, Foundations and Trends in Microeconomics 2(1), 1-108.

[18] Harrington, Joseph E., 2017, A Theory of Collusion with Partial Mutual Understanding, Research in Economics 71(1), 140-158.

[19] Harrington, Joseph E., and Andrzej Skrzypacz, 2011, Private monitoring and communication in cartels: Explaining recent collusive practices, American Economic Review 101(6), 2425-2449.

[20] Igami, Mitsuru, and Takuo Sugaya, 2019, Measuring the Incentive to Collude: The Vitamin Cartels, 1990-1999, unpublished (available at SSRN: https://ssrn.com/abstract $=2889837$ or http://dx.doi.org/10.2139/ssrn.2889837).

[21] Kandori, Michihiro, and Hitoshi Matsushima, 1998, Private observation, communication and collusion, Econometrica 66(3), 627-652.

[22] Kandori, Michihiro, and Ichiro Obara, 1998, Efficiency in Repeated Games Revisited: The Role of Private Strategies, Econometrica 74(2), 499-519.

[23] Kühn, Kai-Uwe, 2001, Fighting collusion by regulating communication between firms, Economic Policy, 16(32), 167-204.

[24] Kühn, Kai-Uwe, 2011, Designing Competition Policy towards Information Exchanges - Looking Beyond the Possibility Results, in OECD, Information Exchanges Between Competitors Under Competition Law, $\operatorname{DAF} / \operatorname{COMP}(2010) 37$.

[25] Levenstein, Margaret C., and Valerie Y. Suslow, 2006, What Determines Cartel Success?, Journal of Economic Literature, 44(1), 43-95.

[26] Mouraviev, Igor, 2014, Explicit Collusion Under Antitrust Enforcement, Center for Mathematic Economics Working Paper $N^{\circ} 494$, Bielefeld university.

[27] Obara, Ichiro, 2009, Folk theorem with communication, Journal of Economic Theory 144, 120-134. 
[28] Pai, Mallesh, Aaron Roth, and Jonathan Ullman, 2017, An Anti-Folk Theorem for Large Repeated Games with Imperfect Monitoring, ACM Transactions on Economics and Computation, 5(2),

[29] Rahman, David, 2014, The Power of Communication, American Economic Review, 104, 3737-3751.

[30] Stigler, George, 1964, A theory of oligopoly, Journal of Political Economy, 72(1), 44-61.

[31] Sugaya, Takuo, and Alexander Wolitzky, 2017, Bounding Equilibrium Payoffs in Repeated Games with Private Monitoring," Theoretical Economics, 691-729.

[32] Sugaya, Takuo, and Alexander Wolitzky, Maintaining Privacy in Cartels, 2018a, Journal of Political Economy, 126, 2569-2607.

[33] Sugaya, Takuo, and Alexander Wolitzky, Bounding Payoffs in Repeated Games with Private Monitoring: n-Player Games, 2018b, Journal of Economic Theory, 175, 58-87.

[34] Wang, Zhongmin, 2009, (Mixed) Strategy in Oligopoly Pricing: Evidence from Gasoline Price Cycles Before and Under a Timing Regulation, Journal of Political Economy, 117(6), 987-1030. 
Figure 1. The existence of a simple collusive equilibrium leading to near-monopoly profits

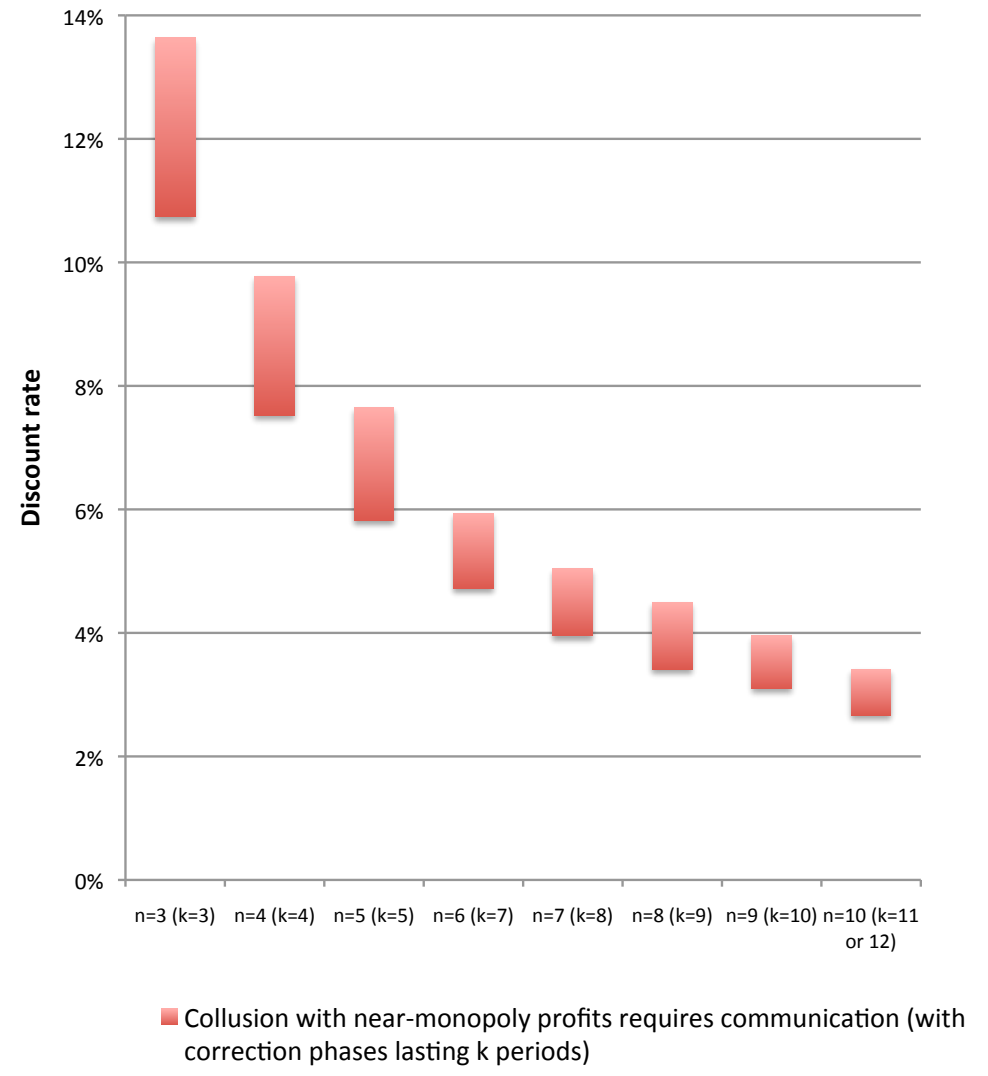

